\title{
Article \\ Heparan Sulfate Deficiency in Cartilage: Enhanced BMP-Sensitivity, Proteoglycan Production and an Anti-Apoptotic Expression Signature after Loading
}

\author{
Matthias Gerstner ${ }^{1}\left(\mathbb{D}\right.$, Ann-Christine Severmann ${ }^{2}$, Safak Chasan ${ }^{1} \mathbb{D}$, Andrea Vortkamp ${ }^{2}$ (D) and Wiltrud Richter ${ }^{1, *(\mathbb{D})}$ \\ 1 Research Centre for Experimental Orthopaedics, Orthopaedic University Hospital Heidelberg, \\ 69118 Heidelberg, Germany; matthias.gerstner@med.uni-heidelberg.de (M.G.); \\ safak.chasan@med.uni-heidelberg.de (S.C.) \\ 2 Department of Developmental Biology, Center for Medical Biotechnology, University of Duisburg-Essen, \\ 45141 Essen, Germany; ann-christine.severmann@uni-due.de (A.-C.S.); andrea.vortkamp@uni-due.de (A.V.) \\ * Correspondence: wiltrud.richter@med.uni-heidelberg.de; Tel.: +49-6221-562-9254
}

check for updates

Citation: Gerstner, M.; Severmann A.-C.; Chasan, S.; Vortkamp, A.; Richter, W. Heparan Sulfate Deficiency in Cartilage: Enhanced BMP-Sensitivity, Proteoglycan Production and an Anti-Apoptotic Expression Signature after Loading. Int. J. Mol. Sci. 2021, 22, 3726. https://doi.org/10.3390/ijms22073726

Academic Editor: Frank Zaucke

Received: 15 March 2021

Accepted: 31 March 2021

Published: 2 April 2021

Publisher's Note: MDPI stays neutral with regard to jurisdictional claims in published maps and institutional affiliations.

Copyright: (c) 2021 by the authors. Licensee MDPI, Basel, Switzerland. This article is an open access article distributed under the terms and conditions of the Creative Commons Attribution (CC BY) license (https:/ / creativecommons.org/licenses/by/ $4.0 /)$.

\begin{abstract}
Osteoarthritis (OA) represents one major cause of disability worldwide still evading efficient pharmacological or cellular therapies. Severe degeneration of extracellular cartilage matrix precedes the loss of mobility and disabling pain perception in affected joints. Recent studies showed that a reduced heparan sulfate (HS) content protects cartilage from degradation in OA-animal models of joint destabilization but the underlying mechanisms remained unclear. We aimed to clarify whether low HS-content alters the mechano-response of chondrocytes and to uncover pathways relevant for HS-related chondro-protection in response to loading. Tissue-engineered cartilage with HS-deficiency was generated from rib chondrocytes of mice carrying a hypomorphic allele of Exostosin 1 (Ext1), one of the main HS-synthesizing enzymes, and wildtype (WT) littermate controls. Engineered cartilage matured for 2 weeks was exposed to cyclic unconfined compression in a bioreactor. The molecular loading response was determined by transcriptome profiling, bioinformatic data processing, and qPCR. HS-deficient chondrocytes expressed 3-6\% of WT Ext1-mRNA levels. Both groups similarly raised Sox9, Col2a1 and Acan levels during maturation. However, HS-deficient chondrocytes synthesized and deposited 50\% more GAG/DNA. TGF $\beta$ and FGF2-sensitivity of Ext1 ${ }^{t / 8 t}$ chondrocytes was similar to WT cells but their response to BMP-stimulation was enhanced. Loading induced similar activation of mechano-sensitive ERK and P38-signaling in WT and HS-reduced chondrocytes. Transcriptome analysis reflected regulation of cell migration as major load-induced biological process with similar stimulation of common (Fosl1, Itg $\alpha$ 5, Timp1, and $\mathrm{Ngf}$ ) as well as novel mechano-regulated genes (Inhba and Dhrs9). Remarkably, only Ext1-hypomorphic cartilage responded to loading by an expression signature of negative regulation of apoptosis with pro-apoptotic Bnip3 being selectively down-regulated. HS-deficiency enhanced BMP-sensitivity, GAG-production and fostered an anti-apoptotic expression signature after loading, all of which may protect cartilage from load-induced erosion.
\end{abstract}

Keywords: heparan sulfate; proteoglycan; mechanical loading; BMP; chondrocytes; cartilage; tissue engineering; agarose; Bnip3

\section{Introduction}

Articular cartilage covers the bone surfaces of diarthrodial joints and allows for painless articulation at low friction. Its composition of collagen fibers interspersed with negatively charged proteoglycans causes immense swelling pressure making it a highly specialized tissue well adapted to shear forces and load bearing [1]. Compared with other connective tissues, articular cartilage has the lowest extracellular-matrix (ECM) turnover and a very limited intrinsic capacity for healing after injury. Therefore, mechanical injuries and overload are major risk factors for the development of osteoarthritis (OA), a syndrome leading to cartilage degradation and dysfunction of the whole joint. OA can, however, in 
part be prevented by mechanical stimulation at physiological levels, which is beneficial for the homeostasis of articular cartilage [2-4].

The high swelling pressure of cartilage is generated by its high density of negatively charged glycosaminoglycans (GAGs). Main GAGs of articular cartilage are chondroitin sulfate (CS), keratan sulfate (KS), dermatan sulfate (DS), and heparan sulfate (HS), with CS being the most abundant, accounting for $10-35 \%$ of cartilage dry weight $[5,6]$. Remarkably, already during early $\mathrm{OA}$, chondrocytes fail to compensate for the loss of GAGs by enhanced synthesis [7-9]. Although the HS-content is 100 times lower than the CS-content in cartilage of porcine articular cartilage, an increasing number of studies suggest a role for $\mathrm{HS}$ in OA-development [10-14]. Reduction in HS-synthesizing (EXT1) or modifying enzymes (NDST1) [12], deletion of the major HS-bearing proteoglycan Syndecan-4 (SDC4) [13], or ablation of the HS-modification of Perlecan (HSPG2) [14] resulted in chondro-protective effects in mouse models after surgical induction of OA. Recently, enhanced expression of several HS-proteoglycans (HSPG) and HS-modifying enzymes was described in human cartilage, further suggesting a role for HS in osteoarthritis [15]. The mechanisms underlying chondro-protection in HS-reduced cartilage are, however, so far not understood.

Surgical OA-models are based on joint-destabilization leading to mechanical overload of articular cartilage; hence, potential mechanisms protecting HS-reduced cartilage from OA-development may center around the mechano-response of chondrocytes. To understand how the HS-proteoglycan content of cartilage may modulate the mechano-response, one has to consider the mechanisms transducing mechanical forces into the biological loading response. In general, three major mechano-transduction paths have been put forward. First, mechanical forces are directly transduced via force-receptors like integrins and cadherins, which are known to be influenced by HS-bearing SDCs, such as SDC1 and SDC4 [16-20]. Second, cell deformation can activate stretch-induced ion channels like TRPC4, TRPC6, and TRPC7, which can interact with HS-bearing SDCs at the cell surface [21-24]. Third, deformation of the ECM causes the release of HS-stored signaling factors, changing their bioavailability and receptor interaction as it was demonstrated for FGF2 and TGF $\beta 1$ [25-27]. Upon loading, HS-stored FGF2 is released from the extracellular matrix, inducing FGFR-signaling and phosphorylation of ERK, a major mechano-response pathway $[25,26]$. HS-interacting TGF $\beta 1$ is stored as latent complex with its pro-domain in the extracellular matrix and can be activated by the release of the inhibiting pro-domain upon force-exertion [27]. In general, effects of HS on sequestration and activation of FGF2, TGF $\beta$, and BMP-signaling are well described [28-30]. Overall, HS and HSPGs may influence all three main mechano-transduction paths underlying the mechano-response of chondrocytes, suggesting that a global approach for molecular characterization of the loading response is important.

Mechanical loading studies in vivo are prone to variances in mechanical loading and artifacts due to the animal or tissue harvest after loading. In contrast, in vitro systems can apply force at defined parameters to homogeneous cartilage specimens to obtain consistent and reliable responses to mechanical loading. Bioreactor systems can imitate physiological conditions, allow for setting of defined loading-parameters and for simultaneous application of force to several tested samples at similar amplitude, frequency, and duration [31,32]. Thereby, mechanical variances, as occurring in vivo, can be prevented.

The access to healthy native cartilage tissue is strongly limited and explants show inherent variabilities, like size, shape, cell number, or matrix content. Tissue engineering (TE) of cartilage was constantly improved over decades as a model system to investigate chondrocyte signaling in vitro [33]. Engineered cartilage is available in higher amounts than native tissue and, due to the in vitro generation, more homogeneous between samples compared to cartilage explants. Maturation of TE-constructs is required to obtain engineered cartilage at similar GAG and collagen content compared to native tissue [31]. Different scaffolds emerged for chondrocyte 3D-culture over the years, which provide different advantages in mimicking human cartilage. While collagen sponges offer strong interaction sites leading to pronounced mechano-responses [31,32], hydrogels are often used 
to induce the spheroidal morphology of chondrocytes and to stabilize their phenotype [34]. Agarose hydrogel has the advantages to provide a defined stiffness and load-transmission and to offer no contact-sites for cells, so the collagens and GAGs involved in cell interaction during loading all derive from the maturing cells themselves. Thus, all interacting proteins and factors in agarose constructs are specific for the cultured cells and offer unique cell type-specific potential for mechano-transduction.

The culture of genetically modified primary chondrocytes from mice enables the generation of mutant 3D-engineered cartilage that can be mechanically challenged. Chondrocytes carrying inactive alleles of specific factors can be cultured and the impact of the deprivation on the mechano-response can be investigated. Chondrocytes with disrupted HS-production are attractive to study the role of the HS-content of cartilage in mechanical loading responses.

Biosynthesis of HS is a multi-step process initiated by the attachment of a linker region to HS-carrying core proteins followed by polymer elongation and the subsequent modification by deacetylation, epimerization, and sulfation [35]. Polymer elongation is catalyzed by the HS-specific glycosyltransferase EXT1, which, in complex with EXT2, transfers alternating glucuronic acid (GlcA) and $\mathrm{N}$-acetylglucosamine (GlcNAc) monomers to the growing polymer chain. Deletion of Ext1 in mice leads to full HS-deficiency and is lethal at E8.5 of embryogenesis due to impaired mesoderm formation [36]. In contrast, $E x t 1^{\text {th/gt }}\left(\right.$ ext $\left.1^{G t(p G T 2 T M p f s) 064 W c s}\right)$ mice [37,38], which carry a hypomorphic allele of Ext1, survive until E16.5 when cartilage of the ribs is already well developed. Rib chondrocytes isolated from $E x t 1^{g^{t} / g t}$ mice represent an ideal cell type for investigating the role of HS for chondrocyte signaling in response to loading.

The aim of this study was to clarify whether low HS-content alters the mechanoresponse of chondrocytes and to uncover HS-related mechanisms relevant for chondroprotection in the context of loading. We hypothesized that low HS-levels will alter the mechano-response of chondrocytes and tested this with our established custom-designed in vitro loading system [31,32] on HS-deficient engineered cartilage generated from ribcage chondrocytes of Ext1 $1^{t / g t}$ mice [37]. To our knowledge, this is the first study addressing whether HS-deficiency impacts the mechano-response of chondrocytes. A better understanding of the chondro-protective mechanisms in HS-deficient cartilage could provide novel therapy options targeting specific molecular pathways to attenuate OA-development and progression.

\section{Results}

\subsection{Elevated Glycosaminoglycan Production in HS-Deficient Engineered Cartilage}

For verification of the Ext1-hypomorphism of native chondrocytes, Ext1 mRNA expression was determined in cultured murine rib-cage chondrocytes (mRCs) from Ext $1^{\text {gt/gt }}$ embryos and WT littermates prior to (d0) and on day 7 and 14 of differentiation culture. Ext1 was expressed at 3-6\% of WT levels in Ext ${ }^{\text {gt/gt }}$ chondrocytes at all tested time points confirming the severely reduced expression of Ext1 (Figure 1A). After 2 weeks of maturation culture, GAGs and Collagen type II had accumulated in cartilage ECM of both groups according to histology (Figure 1B). Staining intensity of the HS-specific epitope 10E4 was low in Ext1-hypomorphic cartilage confirming a strong decrease in HS-levels. Expression of the chondrogenic marker genes Sox9, Col2a1, and Acan rose significantly over time in both groups in a similar manner (Figure 1C). Quantification of proteoglycan deposition revealed a significantly increased GAG/DNA-content in Ext1 ${ }^{\text {th/ }}$ cartilage to about 150\% compared to WT tissue (Figure 1D). Radioactive labeling with ${ }^{35} \mathrm{~S}$-sulfate for $24 \mathrm{~h}$ before culture termination demonstrated significantly enhanced GAG-synthesis in Ext $1^{\text {t/ } / 8 t}$ chondrocytes on day 7 and 14 compared to WT cells (Figure 1E). Conclusively, HS-deficient Ext $1^{\text {gt/gt }}$ chondrocytes produced significantly more sulfated GAGs and accumulated significantly more proteoglycans in engineered cartilage than WT cells. 

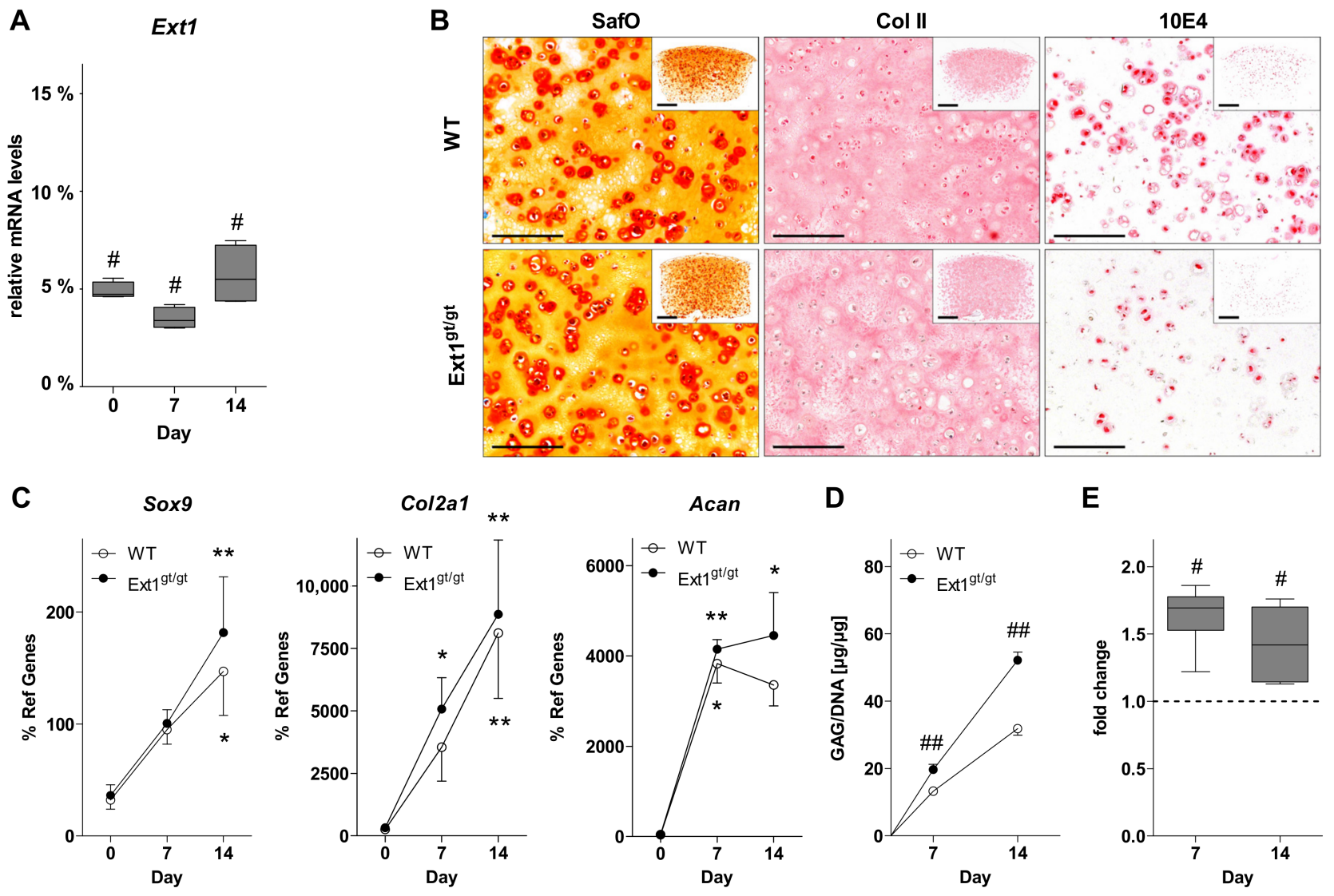

Figure 1. Characterization of Ext1-hypomorphic engineered cartilage. Murine chondrocytes from E15.5 Ext1gt/gt and wildtype (mice were differentiated at $5 \times 10^{5}$ cells per $25 \mu \mathrm{L}$ agarose construct for indicated time-periods under chondrogenic conditions. (A) Ext1 mRNA levels were determined by RT-qPCR and normalized to reference genes Rpl19 and Hprt with WT samples at the indicated timepoints set to $100 \%$. Data are shown as box plots with each box representing the interquartile range and lines inside the boxes representing the median. Whiskers range from minimum to maximum values $(n=4$, 4 donors). (B) Paraffin sections of engineered cartilage on day 14 were stained with Safranin Orange/Fast Green to visualize glycosaminoglycan (GAG) deposition (SafO, $n=22-26,12$ donors) or by immunohistochemistry against Collagen type II (Col II, $n=13-16,6$ donors) and the heparan sulfate (HS)-specific epitope 10E4 (10E4, $n=9-10,5$ donors). Representative images are shown. Scale bar $200 \mu \mathrm{m}$ (Inlays $500 \mu \mathrm{m}$ ). (C) Expression of differentiation markers during cartilage maturation was determined by RT-qPCR and normalized to reference genes Rpl19 and Hprt ( $n=5-6,5-6$ donors). (D) GAG-content of cartilage tissue determined by 1,9-dimethylmethylene blue (DMMB) assay was normalized to DNA-content ( $n=6,3$ donors). (E) GAG de-novo synthesis was determined by ${ }^{35} \mathrm{~S}$-sulfate incorporation over the last $24 \mathrm{~h}$ of differentiation culture. Values were normalized to DNA-content and values of WT cartilage were set to 1 ( $n=6,3$ donors). vs. d0: Kruskal-Wallis ${ }^{*} p<0.05$, ${ }^{* *} p<0.01 ; E x t 1^{g t / g t}$ vs. WT: Mann-Whitney U test $\# p<0.05$, \#\# $p<0.01$.

\subsection{Higher BMP-Sensitivity of HS-Reduced Chondrocytes}

Main effects of HS are exerted on the protein level by affecting growth factor signaling at the cell surface [39-42]. Therefore, we searched for a potential impact of HS-deficiency on TGF $\beta$, FGF, and BMP-pathway activation, which are relevant for cartilage neogenesis. The sensitivity of WT and Ext $1^{g t / g t}$ chondrocytes to growth-factor stimulation was assessed in short-term monolayer culture in the absence of fetal calf serum (FCS). Chondrocytes were exposed to increasing concentrations of TGF $\beta$, FGF2, BMP6, or BMP4, and receptor activation was determined by Western blot analysis. While for both genotypes TGF $\beta$ stimulation similarly induced pSMAD2 (Figure 2A) and FGF2 similarly induced pERK1/2 (Figure 2B) over the full concentration range, BMP-pathway activation differed between genotypes. At all tested BMP4/ 6 concentrations, Ext18t/gt chondrocytes showed a trend towards a stronger BMP-response compared to WT cells, which reached significance under 
stimulation with $10 \mathrm{ng} / \mathrm{mL}$ BMP (Figure 2C). No altered endogenous Bmp-expression in Ext $18^{t / 8 t}$ cartilage samples was recorded compared to WT (Figure S1A). Thus, lower HSlevels enhanced the sensitivity of chondrocytes to pro-chondrogenic BMPs as one possible reason for the enhanced GAG-synthesis observed in HS-deficient cartilage (Figure 1E). To test whether BMP-stimulation would enhance GAG-production in WT chondrocytes, WT specimens were cultured with $10 \mathrm{ng} / \mathrm{mL}$ BMP6 during the last $96 \mathrm{~h}$ of a 7-day maturation culture. In fact, according to ${ }^{35}$ S-sulfate incorporation on day 7, GAG-synthesis was significantly enhanced (Figure 2D), and the GAG/DNA-content of samples increased significantly to the values of Ext1 ${ }^{\text {t/gt }}$ cartilage (Figure 2E). In conclusion, as BMP-pathway activity was rate limiting for GAG-synthesis in WT chondrocytes, the enhanced BMPsensitivity of HS-deficient chondrocytes likely leads to the enhanced GAG-production in Ext1 gt/gt $^{t}$ cartilage.

\subsection{Similar Load-Induced Activation of ERK1/2 and P38 Pathways}

In order to compare the loading-response of WT and Ext1-hypomorphic cartilage, both groups were exposed to a 3-h cyclic unconfined compression episode, which imitates the deformation of human knee-cartilage during $3 \mathrm{~h}$ of normal walking in 10-min intervals (Figure 3A,B). Loading of WT and Ext1-hypomorphic cartilage pre-cultured for 2 weeks resulted in similar stimulation of the common mechano-response pathways ERK1/2 and P38 according to Western blot analysis (Figure 3C). Other than observed before for human engineered cartilage in a collagen carrier [32], expression of Bmp2, Bmp4, and Bmp6 was not altered by loading in both groups (Figure S1B). Furthermore, BMP-signaling was unchanged by loading according to pSMAD1/5/8 levels (data not shown), which is in line with data of a previous study on murine rib chondrocytes in agarose culture [43]. This indicated that lower HS-levels and enhanced BMP-sensitivity had no major impact on the activation of these two common mechano-transduction pathways.

\subsection{Global Molecular Characterization of the Loading Response}

The overall impact of HS-knockdown on the molecular loading response of engineered cartilage was determined by global transcriptome analysis of mechanically challenged cartilage derived from three independent mRC-pools of Ext 1 gt/gt $^{t}$ animals and their WT littermates. Comparison of unloaded control samples of WT and HS-deficient tissue confirmed strong knockdown of Ext1 in Ext1 ${ }^{\text {tt/gt }}$ animals and demonstrated that no compensation regarding alteration of gene expression of other HS-synthesis-related genes occurred (Table S2). Bioinformatic processing of data from loaded vs. non-loaded samples by unpaired Significance Analysis of Microarrays (SAM) analysis indicated that only 2 genes were significantly down-regulated by loading in WT cartilage. However, for both, Exostosin 2 (Ext2) and Smoothened (Smo), this could not be confirmed by RT-qPCR in partially independent samples (data not shown). For the Ext1 ${ }^{g t / g t}$ cartilage group, the same stringent unpaired SAM-analysis delivered 14 genes significantly up-regulated by loading, all of which were induced more than 1.7-fold (Table 1). Only one non-annotated gene was significantly down-regulated (Figure $4 \mathrm{~A}$ ), indicating prevailing cell stimulation. Hierarchical clustering based on the 14 identified hits separated all loaded from non-loaded Ext $1^{\text {gt/ } / 8 t}$ samples, underscoring the validity of recognized targets (Figure 4B). Using the same 14 hits for clustering of the WT group showed that one loaded WT sample clustered with the non-loaded specimens, a heterogeneity, which may explain the lack of valid hits by the chosen stringent SAM-analysis in the WT group (Figure 4C). 
A

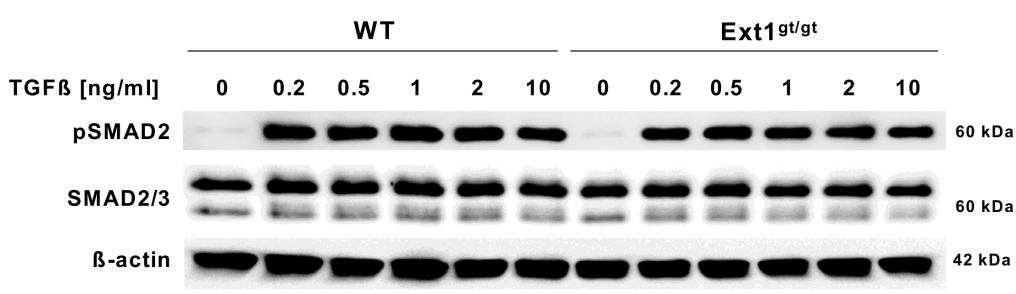

B

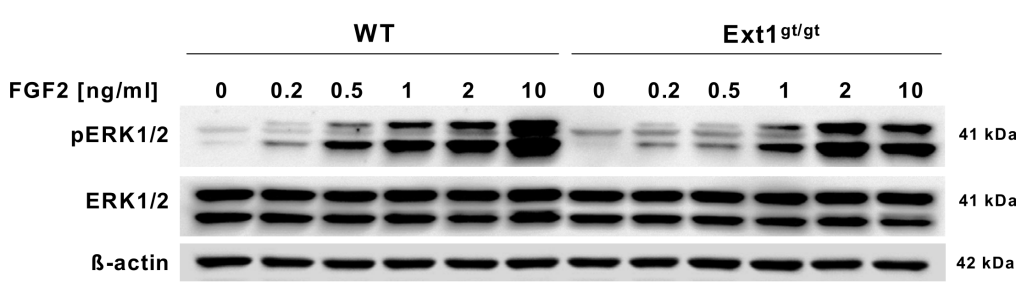

C

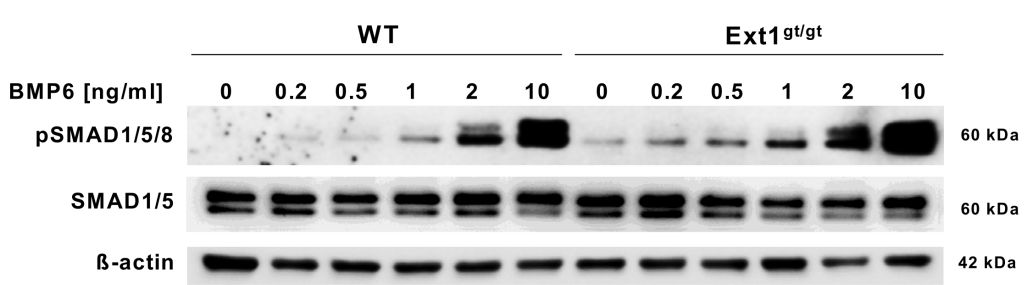

D

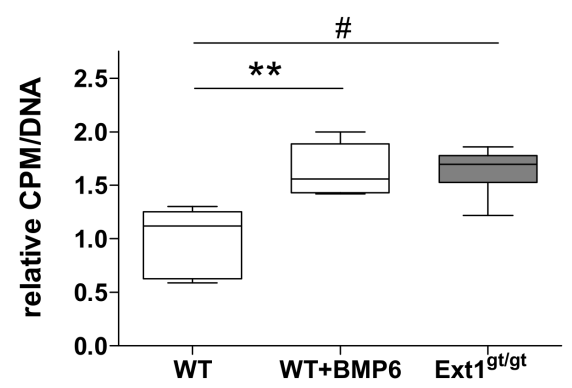

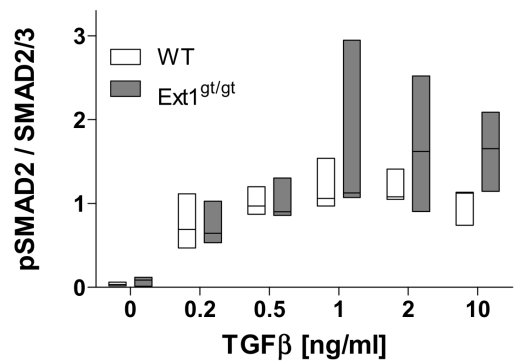
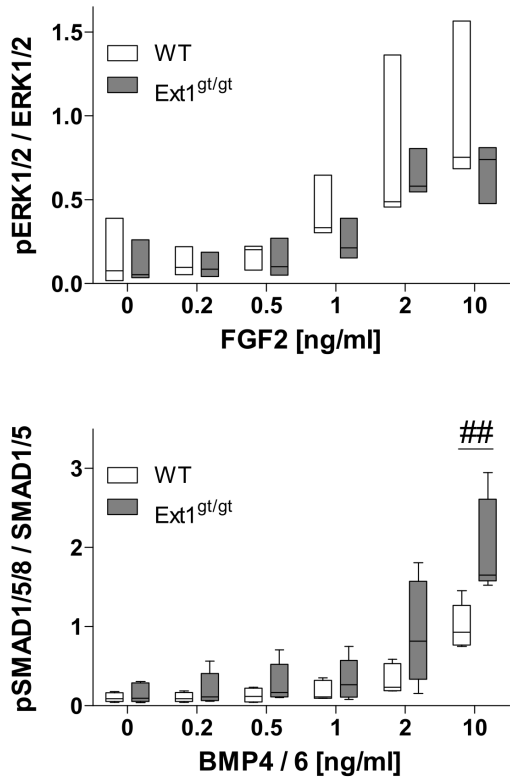

E

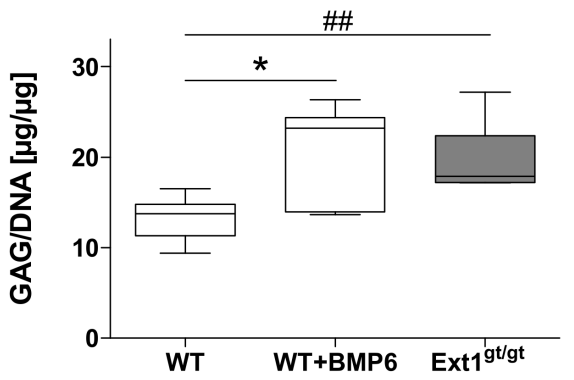

Figure 2. Influence of Ext1-hypomorphism on growth factor signaling and GAG-production of engineered cartilage. (A-C) Ext $1^{\text {gt/gt }}$ and WT chondrocytes were treated in fetal calf serum (FCS)-free monolayer culture with increasing concentrations of indicated growth factors for $3 \mathrm{~h}$. Receptor activation was investigated by Western blot analysis of pSMAD2 /SMAD2/3 (TGF $\beta, n=3,3$ donors), pERK1/2 /ERK1/2 (FGF2, $n=3,3$ donors), and pSMAD1/5/8 /SMAD1/5 (BMP4/6, $n=5,3$ donors) levels with $\beta$-actin used as a loading control. Phosphorylated forms are considered biologically active. Representative blots are shown. Independent blots were standardized by setting the densitometric intensity of WT cells treated with $10 \mathrm{ng} / \mathrm{mL}$ growth factor to 1. (D,E) Engineered WT cartilage was cultured for 7 days under chondrogenic conditions with or without supplementation of $10 \mathrm{ng} / \mathrm{mL}$ BMP6 during the last $96 \mathrm{~h}$ ( $n=6,3$ donors). (D) GAG de-novo synthesis was determined by ${ }^{35} \mathrm{~S}$-sulfate incorporation over the last $24 \mathrm{~h}$ of differentiation culture. Values were normalized to DNA-content and the values of WT controls were set to 1. (E) GAG-content of engineered WT cartilage measured by DMMB assay and normalized to DNA-content. Box plots were generated as described in Figure 1. vs. Ext1 ${ }^{\text {t/gt }}$ (\#)/ untreated (*): Mann-Whitney U test $\# /{ }^{*} p<0.05, \# \# / * * 0.01$. 
A

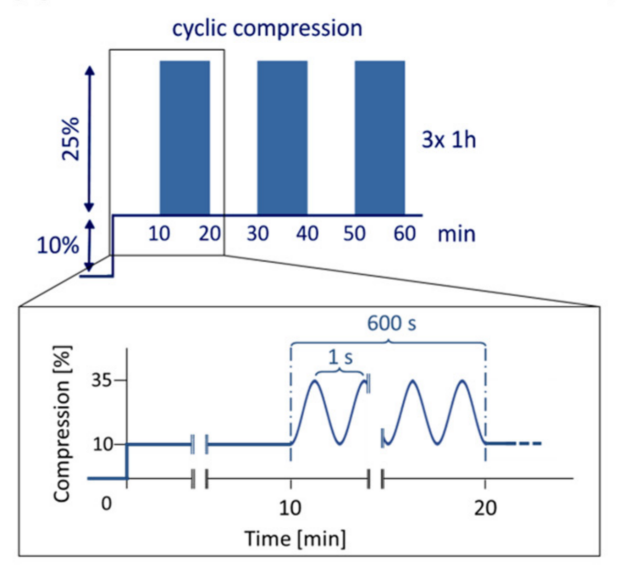

B

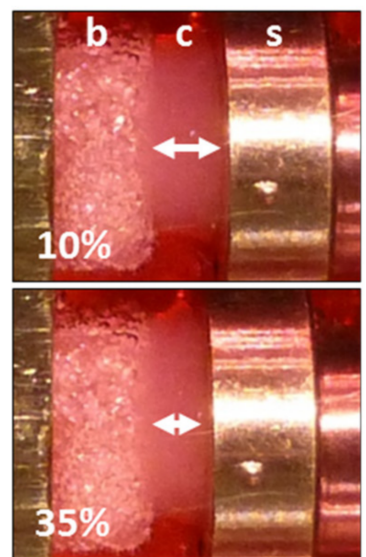

C

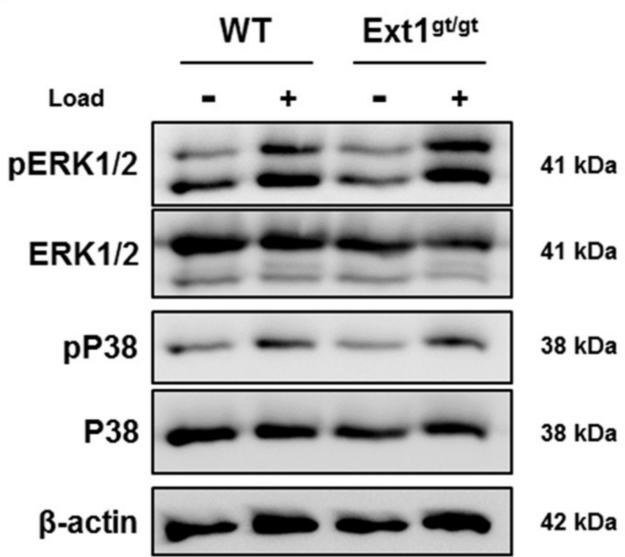

Figure 3. Mechanical loading of engineered cartilage. (A) Schematic representation of the dynamic unconfined compression protocol imitating the impact of $3 \mathrm{~h}$ of normal walking in 10-min intervals. During a 3-h loading episode, dynamic compression at $1 \mathrm{~Hz}$ with an amplitude of $25 \%$ was superimposed on $10 \%$ static-offset. Nine loading intervals were separated by 10-min breaks. (B) Engineered cartilage ("c") attached to a bone replacement phase ("b") was fixed in the loading device. A mobile stamp ("s") applied $10 \%$ static compression (upper picture) that was superimposed by $25 \%$ dynamic compression (lower picture). (C) After 14 days of differentiation culture, Ext1 ${ }^{\text {th }}$ gt and WT cartilage tissue was exposed to the 3-h loading episode $(+)$ or kept unloaded (-). Specimens were snap frozen immediately at termination of loading. Western blot analysis of active pERK1/2 and total ERK1/2 as well as active pP38 and total P38 levels was performed with $\beta$-actin used as a loading control. Representative blots are shown ( $n=6-9,5-6$ donors).

Table 1. Mean microarray expression levels of mRNAs differentially expressed in loaded and nonloaded $E x t 1^{g t / g t}$ samples according to Significance Analysis of Microarrays.

\begin{tabular}{ccccc}
\hline \multirow{2}{*}{ Gene Symbol } & Gene Name & \multicolumn{2}{c}{ Mean Intensities } & \\
\cline { 3 - 4 } & & Ctrl & Load & Fold Change \\
\hline Inhba & Inhibin beta-A & 253 & 1023 & 4.04 \\
Gjb4 & Gap junction protein, beta 4 & 217 & 763 & 3.52 \\
Gprc5a & G protein-coupled receptor C, 5, a & 245 & 760 & 3.11 \\
Timp1 & Tissue inhibitor of MMPs 1 & 988 & 2518 & 2.55 \\
Cd44 & CD44 antigen & 244 & 590 & 2.42 \\
Ngf & Nerve growth factor & 336 & 811 & 2.41 \\
Plaur & PLG-activator, urokinase receptor & 179 & 409 & 2.29 \\
Srxn1 & Sulfiredoxin 1 & 224 & 469 & 2.09 \\
Dusp1 & Dual specificity phosphatase 1 & 1720 & 3590 & 2.09 \\
Fosl1 & Fos-like antigen 1 & 255 & 528 & 2.07 \\
Dhrs9 & Dehydrogenase/reductase 9 & 101 & 209 & 2.06 \\
Nt5e & 5'-nucleotidase, ecto & 593 & 1214 & 2.05 \\
Ucn & Urocortin & 151 & 283 & 1.87 \\
Itga5 & Integrin alpha 5 & 1404 & 2494 & 1.78 \\
\hline
\end{tabular}

bold: genes tested by RT-qPCR.

Next, 7 of the 14 recognized targets were validated by RT-qPCR in partially independent Ext1-hypomorphic samples (bold in Table 1). Mechano-induction of 6/7 genes was confirmed (Figure 4D). Among them were common mechano-sensitive genes like Fosl1, a member of the Fos family of transcription factors known to shape the early loading response [32,43]; Itga5, the main integrin receptor responsible for load transduction in chondrocytes [44,45]; and Ngf, (nerve growth factor) and Timp1, which are known mechanoresponders in chondrocytes $[25,46]$. Beyond, novel mechano-sensitive genes like Inhba and Dhrs9 were discovered. When mechano-regulation of these genes was next tested by RT-qPCR in the WT group in partially independent sample pairs, a significant induction 
was found like in HS-deficient cartilage (Figure 4E). This suggested that less stringent bioinformatic analysis of global transcriptome data should be performed as a next step.

A

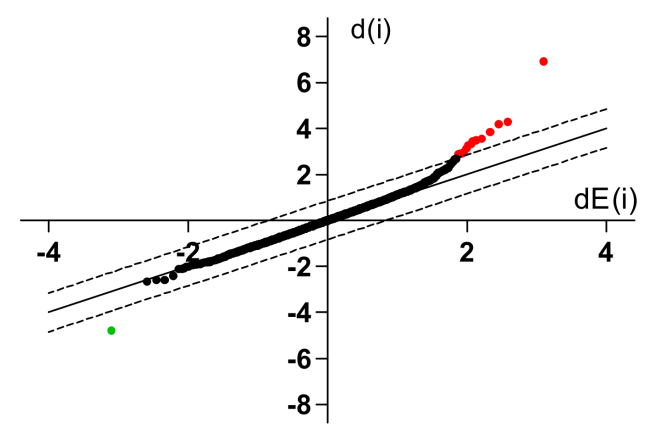

D

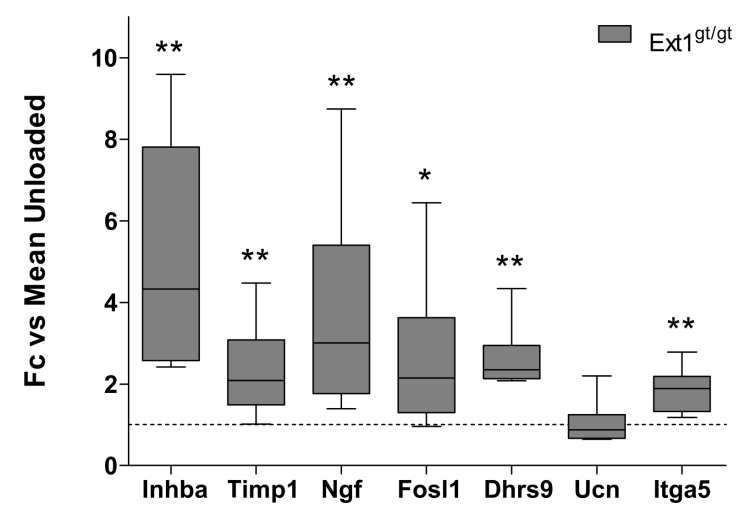

B

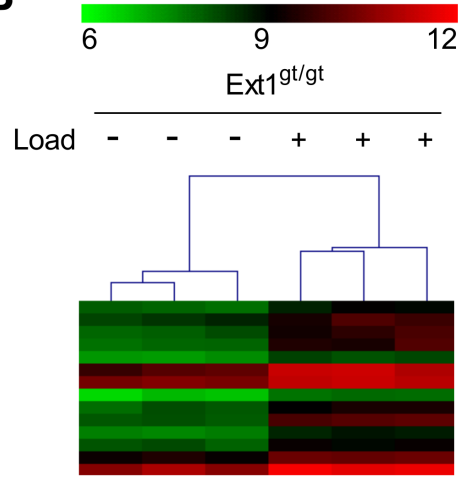

E
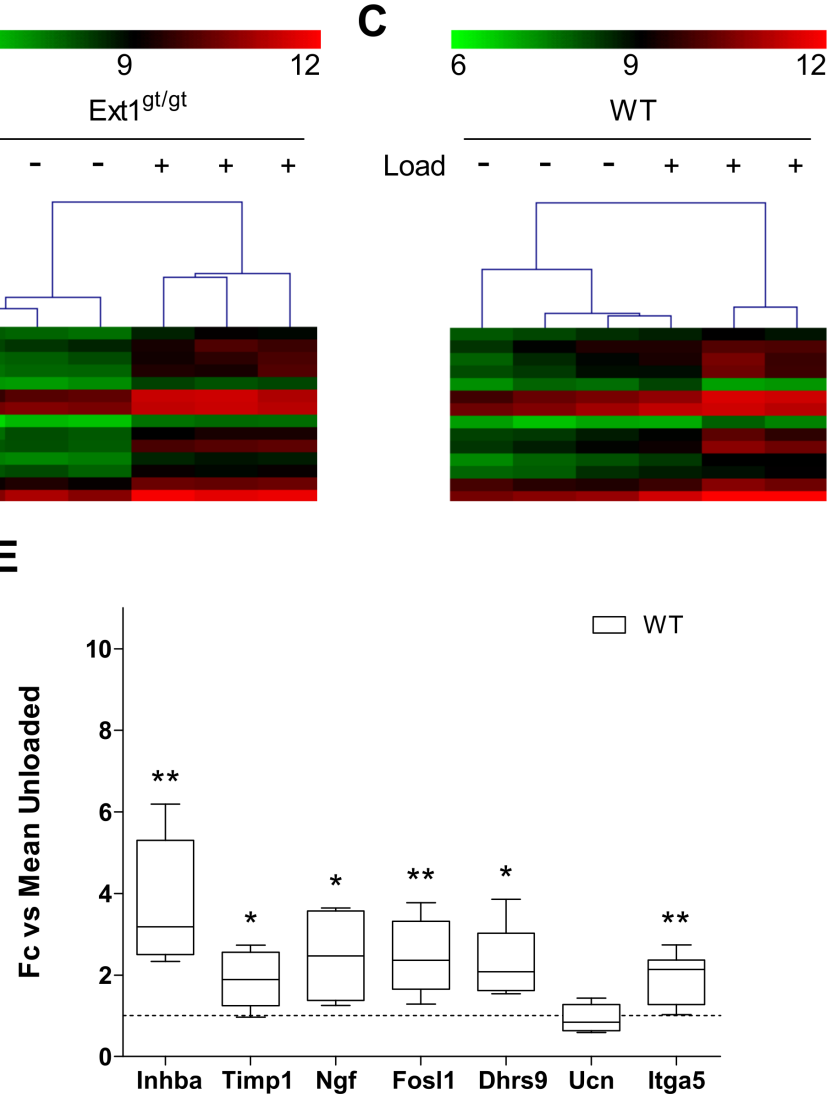

Figure 4. Influence of dynamic compression on global gene expression in HS-deficient and WT cartilage. (A-C) Ext18t/gt and WT cartilage was loaded on day 14 of differentiation culture. Total RNA was isolated from three loaded and non-loaded constructs per group and subjected to whole transcriptome analysis. (A) Microarray results depicted as scatter plot following data processing by Significance Analysis of Microarrays (SAM) comparing loaded and non-loaded Ext $1^{\text {gt/gt }}$ engineered cartilage. The observed relative difference $\mathrm{d}(\mathrm{i})$ was plotted against the expected relative difference $\mathrm{dE}(\mathrm{i})$ for non-loaded and loaded groups. Dashed lines define the difference between $\mathrm{d}(\mathrm{i})$ and $\mathrm{dE}(\mathrm{i})$ beyond which mRNAs were considered significant at a median false discovery rate (FDR) < 0.05. In red: mRNAs significantly higher for loaded vs. non-loaded group; in green: mRNAs significantly lower in loaded vs. non-loaded group. (B) Dendrogram of 14 mRNAs significantly regulated between loaded (+) and non-loaded (-) Ext1 ${ }^{t / / g t}$ samples. (C) Dendrogram of WT samples using the 14 hits from the Ext1 ${ }^{t / / g t}$ groups as input. Data are visualized as heatmap of log-2 transformed intensities ( $n=3,3$ donors). (D,E) Expression levels of

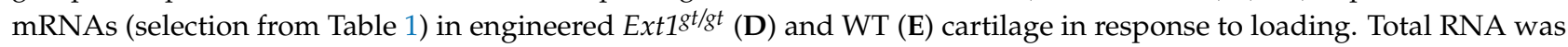
isolated from 6 control and compressed samples per group and subjected to RT-qPCR analysis. Values were normalized to reference genes Hprt and Rpl19 and non-loaded samples were set to 1 (dashed line). Data are shown as box plots as described in Figure 1 ( $n=6,5$ donors). Loaded vs. non-loaded: Mann-Whitney U test ${ }^{*} p<0.05,{ }^{* *} p<0.01$.

\subsection{Induction of an Anti-Apoptotic Expression Signature in HS-Deficient Cartilage by Loading}

According to global microarray data, 112 genes were more than 1.5-fold regulated by loading in WT cartilage (Table S3), while 129 responded more than 1.5-fold in HS-deficient cartilage (Table S4). This indicated a slightly higher sensitivity of HS-reduced cartilage to mechanical loading, which may relate to its higher GAG/DNA-content. As illustrated by Venn diagrams, down-regulated genes hardly overlapped between the two groups, while more than $40 \%$ of the up-regulated genes were common between WT and HS-deficient cartilage (Figure 5A). To obtain an overview on major biological processes regulated by loading, all genes regulated $>1.5$-fold in each genotype were subjected to PANTHER statis- 
tical overrepresentation analysis for "Gene Ontology Biological Process Complete." Using a cutoff at 4-fold overrepresentation (Figure 5B), the category "Regulation of cell migration" was overrepresented in both groups (overrepresentation scores 4.29, $p=0.009\left(E x t 1^{\text {tt/gt }}\right)$ and 4.47, $p=0.011(\mathrm{WT})$ ). Remarkably, "negative regulation of apoptotic process" (overrepresentation score 4.1, $p=0.034$ ), "positive regulation of cell migration" (overrepresentation score 5.34, $p=0.026$ ) and "apoptotic signaling pathway" (overrepresentation score 8.16, $p=0.018)$ were significantly overrepresented only in the Ext18t/gt group but not in the WT group (Figure 5B).

Table 2. Mean microarray expression levels of the genes recorded in the PANTHER "Negative Regulation of Apoptotic Process" category in loaded and non-loaded Ext18t/8t samples.

\begin{tabular}{|c|c|c|c|c|}
\hline \multirow[b]{2}{*}{ Gene Symbol } & \multirow[b]{2}{*}{ Gene Name } & \multicolumn{2}{|c|}{ Mean Intensities } & \multirow[b]{2}{*}{ Fold Change } \\
\hline & & Ctrl & Load & \\
\hline \multicolumn{5}{|l|}{ Up-regulated } \\
\hline $\operatorname{Timp} 1 *$ & Tissue inhibitor of MMPs 1 & 988 & 2518 & 2.55 \\
\hline$N g f^{*}$ & Nerve growth factor & 336 & 811 & 2.41 \\
\hline Dusp1 & Dual specificity phosphatase 1 & 1720 & 3590 & 2.09 \\
\hline Ptgs2 & Prostaglandin $\mathrm{G} / \mathrm{H}$ synthase 2 & 261 & 494 & 1.90 \\
\hline Ucn & Urocortin & 151 & 283 & 1.87 \\
\hline Smo & Smoothened, frizzled class receptor & 189 & 336 & 1.78 \\
\hline $\operatorname{Itga} 5$ * & Integrin alpha 5 & 1404 & 2494 & 1.78 \\
\hline Myc & Myc proto-oncogene protein & 263 & 452 & 1.72 \\
\hline Spry2 & Sprouty homolog 2 & 132 & 207 & 1.56 \\
\hline Jun & Jun proto-oncogene & 406 & 625 & 1.54 \\
\hline$S f n$ & Stratifin, alias $14-3-3$ protein sigma & 155 & 237 & 1.53 \\
\hline Gdf5 & Growth differentiation factor 5 & 376 & 567 & 1.51 \\
\hline \multicolumn{5}{|l|}{ Down-regulated } \\
\hline Bnip3 & BCL2 interacting protein 3 & 1073 & 663 & -1.62 \\
\hline Irs2 & Insulin receptor substrate 2 & 321 & 199 & -1.61 \\
\hline Card14 & $\begin{array}{l}\text { Caspase recruitment domain family, } \\
\text { member } 14\end{array}$ & 134 & 88 & -1.52 \\
\hline
\end{tabular}

bold: genes tested by RT-qPCR, * confirmed genes from SAM-analysis.

The category "negative regulation of apoptotic process" consisted of 15 genes regulated by loading in the Ext1 ${ }^{\text {tgt }}$ group (Table 2). Induction of Timp1, Ngf, Dusp1, and Itga 5 was already recorded by SAM-analysis (Table 1). Beyond, the anti-apoptotic transcription factor $M y c, S f n$, and the growth factor $G d f 5$ were up-regulated, while Card14, a caspase-recruitment domain family member, and Bnip3, a stress-induced pro-apoptotic BCL2-interacting molecule, were down-regulated. Using RT-qPCR analysis, the significant regulation by loading of $M y c$, Sfn, and Bnip3 was confirmed in partially independent sample pairs of Ext ${ }^{g t / g t}$ cartilage (Figure 5C). Importantly, neither induction of anti-apoptotic $S f n$ nor suppression of pro-apoptotic Bnip3 occurred after loading in the WT group (Figure 5D), suggesting that their regulation related to the HS-deficiency of Ext1 gt/gt $^{t}$ cartilage.

The pro-death factor BNIP3 is pro-apoptotic in the mitochondrial pathway and its expression is increased by HIF1 $\alpha$, which is induced under hypoxic conditions. Since mechanical overloading was previously shown to induce HIF1 $\alpha$ in bovine cartilage explants [47], we tested whether our sub-physiological loading protocol affects Hif $1 \alpha$ expression levels. Gene expression of Hif $1 \alpha$ was unaltered by loading in WT and Ext $1^{g t / 8 t}$ cartilage (Figure 5E), indicating that Bnip3 down-regulation in Ext $1^{g t / 8 t}$ cartilage occurred independent of Hif1 $\alpha$. No evidence for load-induced cell death was obtained by a caspase-3 activity assay (data not shown), and mitochondrial activity, detected by an MTT assay performed at the end of loading of day 14 WT samples, reflected no evidence for metabolic stress in response to loading (data not shown). Thus, in the absence of hypoxic and metabolic cell stress, we propose that Bnip3 may be differentially regulated between the genotypes due to a load-induced physical cell-stress response. 
A

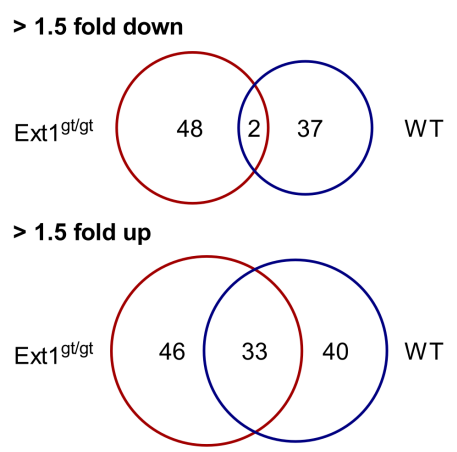

B

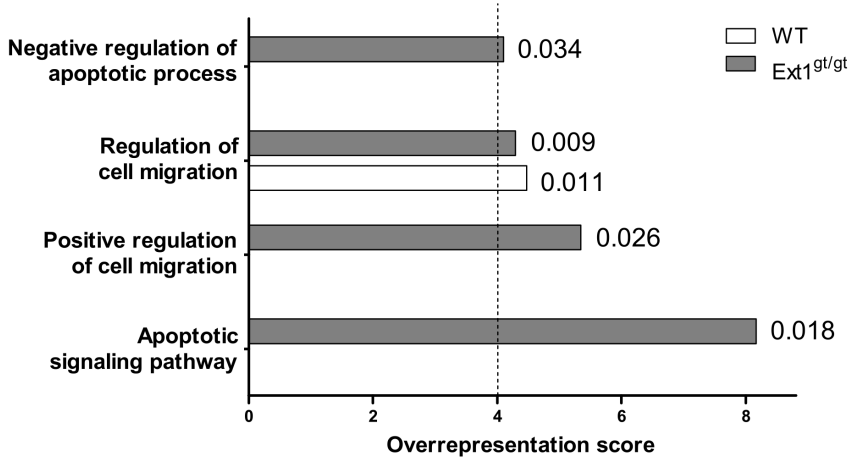

C

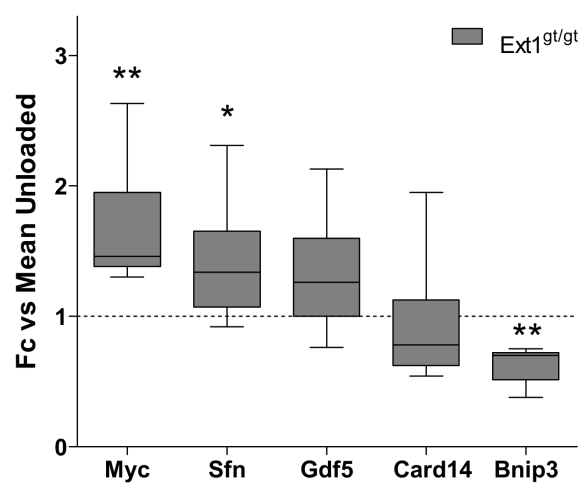

D

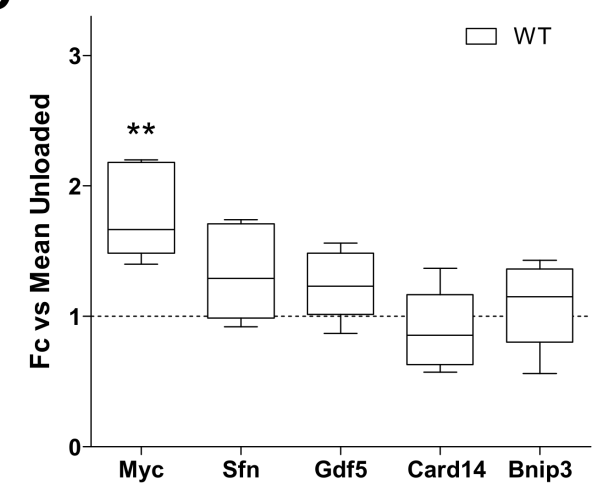

E

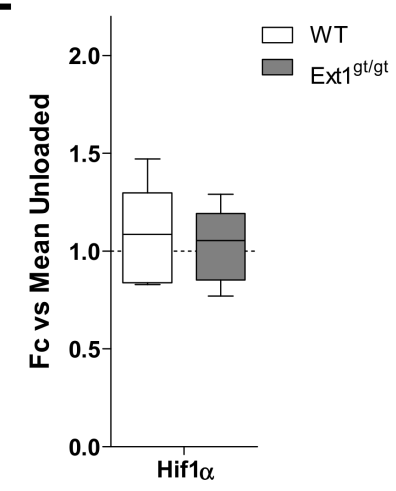

Figure 5. Regulation of mRNA expression ( $>1.5$-fold) in response to loading in HS-deficient and WT cartilage. Microarray data were filtered for genes with a more than 1.5-fold differential expression between loaded and non-loaded samples. (A) Venn diagrams are shown, illustrating the differential and overlapping regulation of mRNAs (>1.5-fold) in Ext1 ${ }^{\mathrm{t} / \mathrm{gt}} \mathrm{vs}$. WT samples by loading. Numbers in Venn diagrams designate the number of regulated genes per group. (B) PANTHER statistical overrepresentation analysis for $E x t 1^{1 / / 8 t}$ and WT cartilage of all genes with a more than 1.5-fold difference in mean expression levels between loaded and non-loaded specimens according to microarray data. Depicted are all Gene Ontology (GO) Biological Process categories with at least 4-fold significant overrepresentation (dashed line) in either genotype according to their overrepresentation score. Numbers behind bars indicate the respective $p$-values. (C,D) Expression levels of mRNAs (selection from Table 2) in engineered Ext1 $1^{t / g t}(\mathbf{C})$ and WT (D) cartilage in response to loading. (E) Expression levels of Hif1 $\alpha$ mRNA in Ext1 ${ }^{t / / g t}$ and WT cartilage in response to loading. RT-qPCR analysis was performed as described in Figure 3. Data are shown as box plots as described in Figure $1(n=6,5$ donors). Loaded vs. non-loaded: Mann-Whitney U test ${ }^{*} p<0.05,{ }^{* *} p<0.01$.

Overall, the data demonstrated that, other than WT cartilage, HS-deficient cartilage gained an anti-apoptotic expression signature after loading and down-regulated expression of the pro-death factor Bnip3, an adjustment that may alter the resistance of cells to stressinduced damage and confer protection against negative effects of loading in cartilage tissue.

\section{Discussion}

Loading is an important regulator of cartilage homeostasis, which can have cartilage maintaining functions in the healthy joint but may also support OA-development under permanent improper overstimulation conditions. Reduced HS-expression in articular cartilage decelerated OA-progression after joint destabilization in animal models; the underlying mechanisms, however, remained so far not well understood [12-14]. Based on a close connection of HSPGs with main players involved in mechano-transduction, we here speculated that a low HS-content of cartilage may positively influence the loading response of chondrocytes, which consequently would enhance the resistance of cartilage to loadinduced degeneration. Our data indicate two likely mechanisms for a better protection of HS-deficient cartilage from deleterious loading: First, a higher BMP-sensitivity of Ext1 ${ }^{t / g t}$ 
chondrocytes at maintained TGF $\beta$ and FGF2-responsiveness corresponded to an elevated production of proteoglycans compared to WT cells; Second, loading induced an antiapoptotic expression signature including up-regulation of anti-apoptotic transcription factors and down-regulation of pro-apoptotic Bnip3, which may enhance the resistance of cells to stress-induced damage. Altogether, overcompensation of HS-loss by enhanced GAG-production and a more beneficial reaction to mechano-induced cell stress seem likely mechanisms enhancing chondro-protection under mechanical stress leading to the reduced degeneration in HS-deficient cartilage.

Proteoglycans play a central role in governing the poroelastic mechanics, electrically mediated swelling forces and stiffness of cartilage. Thus, they are of primary importance for the response of chondrocytes to mechanical loads. We recently demonstrated a positive correlation between the GAG-content of engineered cartilage and an anabolic response of human chondrocytes to loading after cyclic compression and recognized enhanced silencing of anti-chondrogenic WNT signaling by proteoglycans as one underlying mechanism [31]. Since proteoglycans are flushed out from cartilage under dynamic loading [32], a higher GAG-production capacity of cells will allow for faster replenishment of proteoglycans after mechanical loading to restore the pro-chondrogenic microenvironment and stress-shielding capacity of the tissue. In the current study, we showed that BMP-pathway activity was rate limiting for GAG-production in engineered cartilage since WT chondrocytes enhanced GAG-synthesis under slight stimulation with BMP6, which is in line with the literature [48]. Altogether, this underlines that the here-described enhanced BMP-sensitivity of Ext $1^{g t / g t}$ chondrocytes is likely responsible for their enhanced GAG-synthesis and may confer stronger chondro-protection in dynamic loading situations.

A connection of HS-deficiency and BMP-signaling has already been addressed in several studies. Matsumoto et al. described in mice carrying a PRX-Cre-driven loss of function allele of Ext1 that chondrogenesis was delayed and spatial regulation of cartilage condensation was disrupted at maintained pSMAD1/5/8 staining [49]. On the opposite, Huegel et al. reported enhanced BMP-activity in a BMP-reporter assay after treatment of the mesenchymal mouse cell line C3H10T1/2 with the HS-inhibitor Surfen. Furthermore, they observed enhanced chondrogenesis of mouse limb bud cells after Surfen treatment, which was blocked by the BMP-antagonist Noggin [50]. Our study now shows for the first time that mature chondrocytes from rib cages of Ext $1^{g^{t} / g^{t}}$ animals display an enhanced sensitivity to BMP4- and BMP6-stimulation in culture compared to WT cells. This is associated with and may likely cause elevated GAG-synthesis and GAG-deposition in HS-deficient cartilage. In line, data from Bachvarova et al. indicate that $E x t 1^{g t / g t}$ chondrocytes compensate HS-deficiency by overproduction of chondroitin sulfate, likely attached to aggrecan, a major component of the articular cartilage [10]. Increased cartilage matrix formation also occurs in affected tissue of mouse mutants mimicking Hereditary Multiple Exostoses (HME), a disease linked to aberrant Ext1expression [51-53]. Interestingly, in HME, local HS-deficiency co-localizes with ectopic BMP-signaling and excessive cartilage growth in developing long bones to so-called osteochondromas $[49,50]$. Thus, the enhanced BMP4/6-sensitivity and GAG-production discovered here for Ext1 ${ }^{\text {th }} /{ }^{t}$ rib chondrocytes is in line with findings on pharmacological or structural HS-depletion in mesenchymal progenitors and on HS-deficient osteochondroma cells in animal models of HME. Mundy et al. described restraining effects of HS on BMP-ligand availability and BMPR dynamics in Ad-293 cells [40]. Since BMPexpression was similar between WT and Ext $18^{\text {t/gt }}$ cartilage and there was no exogenous BMP in our serum-free differentiation medium, we propose that altered availability of cell-produced BMPs and alterations in ligand-receptor dynamics are likely mechanisms explaining enhanced GAG-production in HS-deficient chondrocytes.

Integrins are main players in sensing of mechanical signals, in regulating cell-matrix interaction and in transducing the signals along the MAPK pathway resulting in ERKactivation [54]. Fibronectin-binding ITGA5 is considered the main integrin mechanoreceptor of chondrocytes $[44,45]$ and its expression is known to be up-regulated in response 
to loading [55]. In line with its basic role in mechano-transduction and rapid adaptation to mechanical challenge, we observed a similar induction of Itga5 expression in WT and mutant cartilage. Furthermore, induction of the same immediate early response genes like Fosl 1 and $N g f$ and a comparable activation of the mechano-sensitive pathways ERK1/2 and P38 in both groups was fostered in response to loading. This suggests that basic mechanisms of force perception via integrin receptors and translation of physical forces into common mechano-transduction pathways are little affected by reduced HS-levels.

The strong mechano-induction of Inhba ( $>4$-fold), a subunit of activin/inhibin complexes belonging to the TGF $\beta$-superfamily, is a novel finding of our study. Two subunits of Inhba form the homodimer Activin A, which signals through canonical ALK4-ACVR2 receptor complexes activating the transcription factors SMAD2 and SMAD3. Activin A has a strong affinity to type 2 receptors, similar to certain BMPs. One important way, how activin A regulates cell behavior, is by antagonizing BMP-ACVR2A/ACVR2B/ALK2 signaling [56]. In WT chondrocytes, BMP-sensitivity, and proteoglycan synthesis were lower than in $E x t 1^{\text {tt/gt }}$ chondrocytes. Therefore, it is tempting to speculate that a potential further reduction in BMP-activity due to load-induced Inhba could be more critical regarding compensation of proteoglycan loss in WT cells than in HS-deficient chondrocytes. Similar up-regulation of Inhba by loading could therefore impact Ext $1^{\text {tt/gt }}$ chondrocytes differentially than WT cells, a possibility that should further be investigated in follow-up studies.

One important novelty of our study is that mechanical loading promoted an overall anti-apoptotic expression signature only in HS-deficient cartilage. Anti-apoptotic genes like the transcription factors Jun and $M y c$ as well as $S f n, N g f$, and $G d f 5$ were up-regulated in response to loading, while pro-apoptotic Bcl-2 interacting protein 3 (Bnip3) was suppressed. Vernon et al. described anti-apoptotic effects for sub-physiological loading of native cartilage plugs after compaction injury and suggested that therapeutic exercises could be designed to deliver sub-physiological loading to the cartilage, thereby minimizing injury [57]. Lee et al. demonstrated that shear stress-induced nitric oxide (NO) is associated with changes in apoptotic regulatory factors that alter chondrocyte metabolism and may contribute to joint degeneration [58]. NO is an important signaling molecule known to be produced in response to mechanical loading $[58,59]$. Remarkably, in hepatocytes, NO-production suppressed the expression of BNIP3 as part of an anti-apoptotic cell response [60]. Thus, it is tempting to speculate that differential NO-production or NO-downstream signaling between WT and HS-deficient cartilage in response to loading may explain the discrepant Bnip3 regulation discovered in this study, an important question that should be answered in future studies.

\section{Materials and Methods}

\subsection{Transgenic Mice}

Mice were kept and bred according to the institutional guidelines of the University of Duisburg-Essen and the University Hospital Essen, specifically approved by the animal welfare officer of the University of Duisburg-Essen. Animal care was approved by the city of Essen (Az: 32-2-11-80-71/ 348) in accordance with § 11 (1) 1a of the "Tierschutzgesetz". Work with transgenic animals was approved by the "Bezirksregierung Duesseldorf" (Az: 53.02.01-D-1.55/12, Anlagen-Nr. 1464) in accordance with $\S 8$ Abs. 4 Satz 2 GenTG of the "Gentechnikgesetz".

Noon of the day, when a vaginal plug was detected, was defined as embryonic day 0.5 (E0.5) of timed pregnancies. Ext1 ${ }^{t / / g t}$ mice were bred by mating heterozygous Ext1 ${ }^{g t}\left(\right.$ ext $\left.1^{\text {Gt(pGT2TMpfs }) 064 W c s}\right)$ mice that were maintained on a C57Bl/6 J background [37]. Genotyping was performed by genomic PCR of tail biopsies as described elsewhere [10].

\subsection{Cell Isolation and Culture}

Primary murine rib-cage chondrocytes (mRCs) were isolated from E15.5 embryonic mice as described elsewhere with adaptations [61]. In short, single ribs were dissected from rib cages in PBS, cleaned manually from perichondrium tissue under the microscope and digested in $2 \mathrm{mg} / \mathrm{mL}$ collagenase-B (Worthington, Lakewood, NJ, USA) in expansion 
medium (DMEM, $1 \mathrm{~g} / \mathrm{L}$ glucose, 10\% FCS, $100 \mathrm{U} / \mathrm{mL}$ penicillin, and $100 \mu \mathrm{g} / \mathrm{mL}$ streptomycin) at $37^{\circ} \mathrm{C}$ for $3 \mathrm{~h}$ with vigorous resuspension every $30 \mathrm{~min}$. mRCs were washed in PBS and plated at 5000 cells $/ \mathrm{cm}^{2}$ in culture flasks and expanded for 6-7 days in expansion medium at $37^{\circ} \mathrm{C}, 5 \% \mathrm{CO}_{2}$.

For investigating growth factor signaling, 80,000 cells/well were plated in 12-well plates $\left(21,000\right.$ cells $\left./ \mathrm{cm}^{2}\right)$ and cultured for 2 days in expansion medium. Cells were rinsed in PBS and stimulated with growth factors for $3 \mathrm{~h}$ in DMEM without FCS. After rinsing in PBS, cells were lysed in $150 \mu \mathrm{L}$ ice-cold RIPA buffer ( $50 \mathrm{mM}$ Tris-HCl, 1\% Triton X-100, 0.1\% SDS, $12 \mathrm{mM}$ sodium deoxycholate, $150 \mathrm{mM} \mathrm{NaCl}, 1 \mathrm{mM}$ EDTA, and $2 \mathrm{mM} \beta$-glycerophosphate) with PefaBloc (Merck, Darmstadt, Germany). Cell debris was removed by centrifugation at 13,000 rcf for $10 \mathrm{~min}$ before Western blot analysis as described below.

\subsection{Generation and Culture of Engineered Cartilage}

At the end of expansion, $\mathrm{mRCs}$ were trypsinized and resuspended in chondrogenic medium (DMEM, $4.5 \mathrm{~g} / \mathrm{L}$ glucose, $0.1 \mathrm{mM}$ dexamethasone, $0.17 \mathrm{mM}$ ascorbic acid-2 phosphate, $1 \mathrm{mM}$ sodium pyruvate, $0.35 \mathrm{mM}$ proline, $100 \mathrm{U} / \mathrm{mL}$ penicillin, and $100 \mu \mathrm{g} / \mathrm{mL}$ streptomycin) containing $1 \%$ ITS+ Premix (Corning, NY, USA) and $10 \mathrm{ng} / \mathrm{mL}$ TGF $\beta$ to obtain a concentration of $6 \times 10^{7}$ cells $/ \mathrm{mL}$. Two volumes of melted $3 \%$ low-melt agarose (peqGOLD, 35-2020, VWR Peqlab, Darmstadt, Germany) at $39^{\circ} \mathrm{C}$ were added to the pre-warmed cell suspension to obtain a final concentration of $2 \times 10^{7}$ cells $/ \mathrm{mL}$ in $2 \%$ agarose. Briefly, $25 \mu \mathrm{L}$ suspension containing $5 \times 10^{5}$ cells were casted into custom-made silicone molds ( $4 \mathrm{~mm}$ in diameter, $2 \mathrm{~mm}$ in height). After solidification at room temperature for $5 \mathrm{~min}$, agarose disks were cultured in $1.5 \mathrm{~mL}$ chondrogenic medium for 2 days and then attached with fibrin gel to custom-made porous glass blocks (ROBU, Hattert, Germany) having approximately $36 \%$ pore volume and $40-100 \mu \mathrm{m}$ pore size, which measured $4 \mathrm{~mm} \times 4 \mathrm{~mm} \times 6 \mathrm{~mm}$. Glass carriers served as a bone-replacement phase to allow medium exchange during culture and loading. Biphasic constructs were cultured for indicated time-periods with medium change every 2-3 days. Where indicated, chondrogenic medium was supplemented with growth factors at the given concentrations.

\subsection{RNA Isolation and RT-qPCR}

Cartilage constructs were snap frozen at harvest and halved before RNA isolation. Total RNA was isolated using the QIAquick Gel Extraction Kit (QIAGEN, Hilden, Germany) with an adapted protocol. In short, half a construct supplemented with $500 \mu \mathrm{L}$ GQ Buffer was disintegrated with a Polytron homogenizer and incubated at $50{ }^{\circ} \mathrm{C}$ for 25 min while shaking to dissolve the agarose carrier and lyse cellular membranes. Briefly, $166 \mu \mathrm{L}$ 2-propanol was added and RNA was purified by silica-membrane columns. cDNA was transcribed using Omniscript RT Kit (Qiagen) with oligo(dT) primers. Quantitative PCR (qPCR) was performed with SYBR green (Thermo Fisher, Waltham, MA, USA) using primers listed in Table S1. Genes were considered expressed only if agarose gel electrophoresis of PCR reactions revealed distinct bands at the correct running height and only single melting peaks at the correct temperature appeared during qPCR. Expression levels were calculated using the $\Delta \mathrm{Ct}$ method vs. the arithmetic mean of two reference genes, Hprt and Rpl19. Depicted \% reference genes (\% Ref Genes) was calculated as $1.8^{\wedge}(-\Delta \mathrm{Ct}) \times 100$.

\subsection{Histology}

Cartilage constructs were fixed in $4 \%$ formaldehyde and dehydrated in increasing concentrations of 2-propanol and acetone before paraffin-embedding. For histology, $5 \mu \mathrm{m}$ sections were cut, de-paraffinized, and rehydrated. Sulfated glycosaminoglycans (GAGs) were stained with $0.2 \%(\mathrm{~m} / \mathrm{V})$ Safranin O (Fluka, Sigma Aldrich, St. Louis, MO, USA) in $1 \%$ acetic acid and $0.04 \%(\mathrm{~m} / \mathrm{V})$ Certistain Fast Green (Merck) in $0.2 \%$ acetic acid as counter-staining. For immunohistochemistry (IHC) against Collagen type II and heparan sulfate (10E4-epitope), rehydrated sections were subsequently digested with $4 \mathrm{mg} / \mathrm{mL}$ hyaluronidase in PBS, $\mathrm{pH} 5.5$, at $37^{\circ} \mathrm{C}$ for 15 min for antigen retrieval. Collagen type II- 
stained sections were additionally digested with $1 \mathrm{mg} / \mathrm{mL}$ pronase in PBS, $\mathrm{pH} 7.4$, at $37^{\circ} \mathrm{C}$ for $30 \mathrm{~min}$. Blocking in 5\% BSA (Sigma Aldrich) was followed by incubation with primary antibody against human Collagen type II (1:1000, ICN Biomedicals, Eschwege, Germany, clone II-4C11) or an HS-specific epitope (1:200, AMS Biotechnology, Abingdon, UK, clone F58-10E4). The BrightVision Poly-AP-Anti Ms/Rb IgG, one component kit (ImmunoLogik, Duiven, The Netherlands) and ImmPACT Vector Red (Vector, Peterborough, UK) as alkaline phosphatase substrate were used for detection and Collagen type II-stained sections were counterstained with Mayer's Hematoxylin. Slides were permanently mounted with NeoMount (SafO, Merck) or Aquatex (IHC, Merck) before light microscopy.

\subsection{GAG and DNA-Quantification}

Constructs were digested with $0.5 \mathrm{mg} / \mathrm{mL}$ Proteinase $\mathrm{K}$ (Thermo Fisher) in digestion buffer (50 mM Tris- $\mathrm{HCl}, 1 \mathrm{mM} \mathrm{CaCl}, \mathrm{pH} 8)$ at $65^{\circ} \mathrm{C}$ while shaking overnight. Concentrations of GAGs within the digests were quantified by the 1,9-dimethylmethylene blue (DMMB) assay using chondroitin-sulfate A (Sigma Aldrich) as a standard [62]. DNA was quantified with Quant-iT ${ }^{\mathrm{TM}}$-PicoGreen ${ }^{\circledR}$ (Life Technologies, Thermo Fisher). The GAG-content was normalized to the DNA content.

\subsection{GAG-Synthesis}

De-novo synthesis of highly sulfated GAGs was determined by ${ }^{35}$ S-sulfate incorporation. Tissue-engineered cartilage was posed on a nylon mesh in a 48-well plate to allow full contact to $500 \mu \mathrm{L}$ chondrogenic medium supplemented with $4 \mu \mathrm{Ci}^{35} \mathrm{SO}_{4}$ (Hartmann Analytic, Braunschweig, Germany, ARS0105). Label incorporation was performed in the incubator at $37^{\circ} \mathrm{C}, 5 \% \mathrm{CO}_{2}$ for $24 \mathrm{~h}$. After 5 washing steps in $500 \mu \mathrm{L} 1 \mathrm{mM} \mathrm{Na}_{2} \mathrm{SO}_{4}$ in PBS for 20 min while shaking, samples were digested with Proteinase K as described for GAG and DNA-quantification. Incorporated label was quantified by $\beta$-scintillation counting using the program Winspectral. Radioactivity was normalized to DNA-content determined as described above.

\subsection{Mechanical Loading}

The last change of chondrogenic medium was performed $24 \mathrm{~h}$ prior to mechanical stimulation. Tissue-engineered cartilage together with the medium was transferred into our custom-built bioreactor system $2 \mathrm{~h}$ before loading [32]. Cartilage was pre-compressed at $10 \%$ of its thickness (static-offset) to maintain contact to the piston throughout compression. For $3 \mathrm{~h}, 10$-min intervals of static offset were intermitted by superimposition of $25 \%$ dynamic compression at $1 \mathrm{~Hz}$ for $10 \mathrm{~min}$. Free-swelling controls were kept in the same device without loading. Samples were snap frozen directly after the end of the last dynamic loading interval and stored at $-80^{\circ} \mathrm{C}$ until processed.

\subsection{Protein Lysates and Western Blot}

Half a construct was disintegrated in $75 \mu \mathrm{L}$ PhosphoSafe Extraction Reagent (Merck Millipore) supplemented with $1 \mathrm{mM}$ Pefabloc SC (Merck) using a mixer mill (Retsch, Haan, Germany) at $30 \mathrm{~Hz}$ for $2 \times 2 \mathrm{~min}$ and cell debris was removed by centrifugation at 13,000 rcf for $20 \mathrm{~min}$. Proteins were separated by denaturing SDS-gel electrophoresis in $10 \%$ poly-acrylamide gels before blotting on a nitrocellulose membrane (GE Healthcare, Berlin, Germany). To stain proteins of different heights in parallel, the membrane was cut at $50 \mathrm{kDa}$. Blocking in 5\% milk powder in $0.05 \%$ TBST for $1 \mathrm{~h}$ was followed by incubation with primary antibody against $p$-ERK1/2 (1:200, Santa Cruz, Dallas, TX, US, sc-7383, clone E-4), ERK1/2 (1:1000, Cell Signaling Technology, Danvers, MA, US, 9102), pP38 (1:1000, Cell Signaling Technology, 4511, clone D3F9), P38 (1:1000, Cell Signaling Technology, 9212), pSMAD2 (1:250, Cell Signaling Technology, 3108, clone 138D4), SMAD2/3 (1:1000, Cell Signaling Technology, 8685, clone D7G7), pSMAD1/5/8 (1:250, Cell Signaling Technology, 13820S), SMAD1 (1:500, Abcam, Cambridge, UK, Ab33902, clone EP565Y), SMAD5 (1:1000, Abcam, Ab40771, clone EP619Y), or $\beta$-actin (1:10,000, GeneTex, Irvine, CA, US, GTX26276, 
clone AC-15) in 5\% milk overnight at $4{ }^{\circ} \mathrm{C}$. Membranes were washed $3 \times 5$ min and incubated with secondary antibodies in 5\% milk that were peroxidase-conjugated goat anti-mouse (1:5000, Jackson ImmunoResearch, Cambridge, UK, 111-035-046) or goat antirabbit (1:10,000, Jackson ImmunoResearch, 115-035-071) IgGs for $2 \mathrm{~h}$ at room temperature. Membranes were washed $3 \times 5$ min and the Western Bright Chemiluminescence Substrate kit (Biozym, Hessisch Oldendorf, Germany) was used for detection in the Fusion-SL 3500 WL imaging system (VWR Peqlab).

\subsection{Caspase 3 Activation and MTT Assay}

For the caspase assay, cartilage specimens were incubated with $0.1 \mu \mathrm{g} / \mathrm{mL}$ fluorescein diacetate in PBS for $5 \mathrm{~min}$ at $37^{\circ} \mathrm{C}$, snap frozen, and lysed (50 mM HEPES, 1.5\% CHAPS, $2 \mathrm{mM}$ DTT). Briefly, $100 \mu \mathrm{L}$ lysate was incubated with $100 \mu \mathrm{L} 20 \mu \mathrm{M}$ Ac-DEVD-AMC (Biomol) in assay buffer (20 mM HEPES, 2 mM EDTA, 0.1\% CHAPS, and 2 mM DTT). Fluorescence of cleaved substrate was normalized to fluorescein. For the MTT-assay, $0.2 \mathrm{mg} / \mathrm{mL}$ MTT (3-(4,5-Dimethylthiazol-2-yl)-2,5-Diphenyltetrazolium Bromide) was supplemented to the medium for $2 \mathrm{~h}$. MTT-formazan was solubilized with 2-propanol and quantified photometrically.

\subsection{Microarray Analysis}

Total RNA was isolated as described above and subjected to mRNA expression analysis using the Clariom ${ }^{\mathrm{TM}} \mathrm{S}$ Assay, mouse (Affymetrix/Thermo) detecting expression levels of >20,000 mRNAs. RNA quality control, labeling, array hybridization, and microarray scanning were performed at the Genomics and Proteomics Core Facility at the German Cancer Research Center, Heidelberg. Intensity values from cDNA array analysis were quantile-normalized, log2-transformed, and analyzed in MultiExperiment Viewer 4.9.0 (TM4 Microarray-Software-Suite). Venn diagrams were calculated using the Bioinformatics \& Evolutionary Genomics website: http:/ / bioinformatics.psb.ugent.be/webtools/Venn/ (accessed on 20 December 2019). PANTHER overrepresentation analysis was performed for the PANTHER Gene Ontology (GO)-Biological Process Complete category, submitting the list of all genes with a more than 1.5-fold differential mean expression between loaded and non-loaded samples to the PANTHER software (Version 15.0, released 2020-02-14; Mi et al. 2019). Overrepresentation was tested by Fisher's exact test with Bonferroni correction for multiple testing using the Mus musculus database (DOI:10.5281/zenodo.4081749 Released 2020-10-09) as reference list. Microarray data were further analyzed by unpaired Significance Analysis of Microarrays (SAM) [63]. For multiple testing in SAM-analysis, correction with the median false discovery rate (FDR) set to $<0.05$ was applied. Each engineered cartilage construct was considered an independent biological sample.

\subsection{Statistics}

Timelines are presented as means with SEM. For multiple comparisons in time courses, Kruskal-Wallis with Dunn's multiple comparison test was performed. Group comparisons are depicted as box plots visualizing the interquartile range around the median (line) with whiskers ranging from minimum to maximum values. Statistical significance between groups was tested by non-parametric Mann-Whitney $U$ test with Bonferroni correction in case of multiple comparisons. For all comparisons, the mean of all controls was set to 1. A probability value of $p<0.05$ was considered statistically significant. Data analysis was performed using GraphPad Prism 9.

\section{Conclusions}

Altogether, our data identified two likely mechanisms for an improved protection of HS-deficient cartilage from load-induced degeneration: superior GAG-production likely due to an enhanced BMP-sensitivity of HS-deficient chondrocytes and an anti-apoptotic expression signature gained by loading, which we consider as a more favorable downstream mechano-response compared to WT cartilage. Beyond the basic value of our data and new 
ideas about diagnostic and therapeutic targets in HS-relevant pathways, better knowledge of HS-related chondro-protection may allow to design pharmacological treatments to reduce HS-levels and combine them with therapeutic exercises to deliver sub-physiological loading to the cartilage in early OA or after cartilage injury.

Supplementary Materials: The following are available online at https://www.mdpi.com/article/ 10.3390/ijms22073726/s1, Figure S1: Expression levels of selected Bmps during cartilage maturation and in response to loading in HS-deficient and WT cartilage, Table S1: qPCR primer list, Table S2: Expression of selected genes related to heparan sulfate synthesis in WT and Ext 1 gt/ $^{t}$ t engineered cartilage according to cDNA array analysis, Table S3: Expression of genes regulated $>1.5$-fold in WT cartilage in response to loading, Table S4: Expression of genes regulated >1.5-fold in Ext1 gt/gt $^{t}$ cartilage in response to loading.

Author Contributions: Conceptualization, M.G. and W.R.; investigation, M.G.; methodology, M.G.; data curation, M.G. and S.C.; visualization, M.G.; formal analysis, M.G., S.C. and W.R.; resources, A.-C.S. and A.V.; writing—original draft preparation, M.G. and W.R.; writing—review and editing, M.G., A.-C.S., S.C., A.V. and W.R.; project administration, W.R.; funding acquisition, W.R. All authors have read and agreed to the published version of the manuscript.

Funding: This study was supported by the German Research Foundation DFG-grants RI707/12-1 and RI707/12-2 as part of the Excarbon Research Group FOR2407.

Institutional Review Board Statement: Mice were kept and bred according to the institutional guidelines of the University of Duisburg-Essen and the University Hospital Essen, specifically approved by the animal welfare officer of the University of Duisburg-Essen. Animal care was approved by the city of Essen (Az: 32-2-11-80-71/ 348) in accordance with § 11 (1) 1a of the "Tierschutzgesetz." Work with transgenic animals was approved by the "Bezirksregierung Duesseldorf" (Az: 53.02.01-D-1.55/12, Anlagen-Nr. 1464) in accordance with § 8 Abs. 4 Satz 2 GenTG of the "Gentechnikgesetz."

Informed Consent Statement: Not applicable.

Data Availability Statement: The cDNA microarray data described in this manuscript can be found on: https://www.ebi.ac.uk/arrayexpress/E-MTAB-10258.

Acknowledgments: We thank Attila Aszódi, Paolo Alberton (LMU Munich), and Nicole Hecht for advice in the isolation of murine rib-cage chondrocytes, Jörg Fellenberg who kindly contributed his expertise on apoptosis assays, and Solvig Diederichs for revising the manuscript.

Conflicts of Interest: The authors declare no conflict of interest.

\section{References}

1. Poole, A.R.; Kojima, T.; Yasuda, T.; Mwale, F.; Kobayashi, M.; Laverty, S. Composition and structure of articular cartilage: A template for tissue repair. Clin. Orthop. Relat. Res. 2001, 391, S26-S33. [CrossRef] [PubMed]

2. Vannini, F.; Spalding, T.; Andriolo, L.; Berruto, M.; Denti, M.; Espregueira-Mendes, J.; Menetrey, J.; Peretti, G.M.; Seil, R.; Filardo, G. Sport and early osteoarthritis: The role of sport in aetiology, progression and treatment of knee osteoarthritis. Knee Surg. Sports Traumatol. Arthrosc. Off. J. Esska 2016, 24, 1786-1796. [CrossRef]

3. Valderrabano, V.; Steiger, C. Treatment and Prevention of Osteoarthritis through Exercise and Sports. J Aging Res 2010, 2011, 374653. [CrossRef] [PubMed]

4. Iijima, H.; Ito, A.; Nagai, M.; Tajino, J.; Yamaguchi, S.; Kiyan, W.; Nakahata, A.; Zhang, J; Wang, T.; Aoyama, T.; et al. Physiological exercise loading suppresses post-traumatic osteoarthritis progression via an increase in bone morphogenetic proteins expression in an experimental rat knee model. Osteoarthr. Cartil. 2017, 25, 964-975. [CrossRef]

5. Venn, M.; Maroudas, A. Chemical composition and swelling of normal and osteoarthrotic femoral head cartilage. I. Chemical composition. Ann. Rheum. Dis. 1977, 36, 121-129. [CrossRef] [PubMed]

6. Palukuru, U.P.; McGoverin, C.M.; Pleshko, N. Assessment of hyaline cartilage matrix composition using near infrared spectroscopy. Matrix Biol. J. Int. Soc. Matrix Biol. 2014, 38, 3-11. [CrossRef] [PubMed]

7. Cs-Szabo, G.; Roughley, P.J.; Plaas, A.H.; Glant, T.T. Large and small proteoglycans of osteoarthritic and rheumatoid articular cartilage. Arthritis Rheum. 1995, 38, 660-668. [CrossRef] [PubMed]

8. Malemud, C.J.; Papay, R.S.; Hering, T.M.; Holderbaum, D.; Goldberg, V.M.; Haqqi, T.M. Phenotypic modulation of newly synthesized proteoglycans in human cartilage and chondrocytes. Osteoarthr. Cartil. 1995, 3, 227-238. [CrossRef]

9. Venkatesan, N.; Barre, L.; Bourhim, M.; Magdalou, J.; Mainard, D.; Netter, P.; Fournel-Gigleux, S.; Ouzzine, M. XylosyltransferaseI regulates glycosaminoglycan synthesis during the pathogenic process of human osteoarthritis. PLoS ONE 2012, 7, e34020. [CrossRef] 
10. Bachvarova, V.; Dierker, T.; Esko, J.; Hoffmann, D.; Kjellen, L.; Vortkamp, A. Chondrocytes respond to an altered heparan sulfate composition with distinct changes of heparan sulfate structure and increased levels of chondroitin sulfate. Matrix Biol. J. Int. Soc. Matrix Biol. 2020, 93, 43-59. [CrossRef]

11. Vynios, D.H.; Papadas Th, A.; Faraos, A.; Mastronikolis, N.S.; Goumas, P.; Tsiganos, C.P. A solid phase assay for the determination of heparan sulfate and its application to normal and cancerous human cartilage samples. J. Immunoass. Immunochem. 2001, 22, 337-351. [CrossRef]

12. Severmann, A.C.; Jochmann, K.; Feller, K.; Bachvarova, V.; Piombo, V.; Stange, R.; Holzer, T.; Brachvogel, B.; Esko, J.; Pap, T.; et al. An altered heparan sulfate structure in the articular cartilage protects against osteoarthritis. Osteoarthr. Cartil. 2020, 28, 977-987. [CrossRef]

13. Echtermeyer, F.; Bertrand, J.; Dreier, R.; Meinecke, I.; Neugebauer, K.; Fuerst, M.; Lee, Y.J.; Song, Y.W.; Herzog, C.; Theilmeier, G.; et al. Syndecan-4 regulates ADAMTS-5 activation and cartilage breakdown in osteoarthritis. Nat. Med. 2009, 15, 1072-1076. [CrossRef]

14. Shu, C.C.; Jackson, M.T.; Smith, M.M.; Smith, S.M.; Penm, S.; Lord, M.S.; Whitelock, J.M.; Little, C.B.; Melrose, J. Ablation of Perlecan Domain 1 Heparan Sulfate Reduces Progressive Cartilage Degradation, Synovitis, and Osteophyte Size in a Preclinical Model of Posttraumatic Osteoarthritis. Arthritis Rheumatol. (Hobokenn. J.) 2016, 68, 868-879. [CrossRef]

15. Chanalaris, A.; Clarke, H.; Guimond, S.E.; Vincent, T.L.; Turnbull, J.E.; Troeberg, L. Heparan Sulfate Proteoglycan Synthesis Is Dysregulated in Human Osteoarthritic Cartilage. Am. J. Pathol. 2019, 189, 632-647. [CrossRef]

16. Beauvais, D.M.; Ell, B.J.; McWhorter, A.R.; Rapraeger, A.C. Syndecan-1 regulates alphavbeta3 and alphavbeta5 integrin activation during angiogenesis and is blocked by synstatin, a novel peptide inhibitor. J. Exp. Med. 2009, 206, 691-705. [CrossRef]

17. Vuoriluoto, K.; Jokinen, J.; Kallio, K.; Salmivirta, M.; Heino, J.; Ivaska, J. Syndecan-1 supports integrin alpha2beta1-mediated adhesion to collagen. Exp. Cell Res. 2008, 314, 3369-3381. [CrossRef]

18. Bass, M.D.; Roach, K.A.; Morgan, M.R.; Mostafavi-Pour, Z.; Schoen, T.; Muramatsu, T.; Mayer, U.; Ballestrem, C.; Spatz, J.P.; Humphries, M.J. Syndecan-4-dependent Rac1 regulation determines directional migration in response to the extracellular matrix. J. Cell Biol. 2007, 177, 527-538. [CrossRef]

19. McQuade, K.J.; Beauvais, D.M.; Burbach, B.J.; Rapraeger, A.C. Syndecan-1 regulates alphavbeta5 integrin activity in B82L fibroblasts. J. Cell Sci. 2006, 119, 2445-2456. [CrossRef]

20. Langhe, R.P.; Gudzenko, T.; Bachmann, M.; Becker, S.F.; Gonnermann, C.; Winter, C.; Abbruzzese, G.; Alfandari, D.; Kratzer, M.C.; Franz, C.M.; et al. Cadherin-11 localizes to focal adhesions and promotes cell-substrate adhesion. Nat. Commun. 2016, 7, 10909. [CrossRef]

21. Gopal, S.; Sogaard, P.; Multhaupt, H.A.; Pataki, C.; Okina, E.; Xian, X.; Pedersen, M.E.; Stevens, T.; Griesbeck, O.; Park, P.W.; et al. Transmembrane proteoglycans control stretch-activated channels to set cytosolic calcium levels. J. Cell Biol. 2015, 210, 1199-1211. [CrossRef] [PubMed]

22. Liu, Y.; Echtermeyer, F.; Thilo, F.; Theilmeier, G.; Schmidt, A.; Schulein, R.; Jensen, B.L.; Loddenkemper, C.; Jankowski, V.; Marcussen, N.; et al. The proteoglycan syndecan 4 regulates transient receptor potential canonical 6 channels via RhoA/Rhoassociated protein kinase signaling. Arter. Thromb. Vasc. Biol. 2012, 32, 378-385. [CrossRef]

23. Couchman, J.R. Transmembrane signaling proteoglycans. Annu. Rev. Cell Dev. Biol. 2010, 26, 89-114. [CrossRef] [PubMed]

24. Mitsou, I.; Multhaupt, H.A.B.; Couchman, J.R. Proteoglycans, ion channels and cell-matrix adhesion. Biochem. J. 2017, 474, 1965-1979. [CrossRef] [PubMed]

25. Vincent, T.L.; Hermansson, M.A.; Hansen, U.N.; Amis, A.A.; Saklatvala, J. Basic fibroblast growth factor mediates transduction of mechanical signals when articular cartilage is loaded. Arthritis Rheum. 2004, 50, 526-533. [CrossRef] [PubMed]

26. Vincent, T.L.; McLean, C.J.; Full, L.E.; Peston, D.; Saklatvala, J. FGF-2 is bound to perlecan in the pericellular matrix of articular cartilage, where it acts as a chondrocyte mechanotransducer. Osteoarthr. Cartil. 2007, 15, 752-763. [CrossRef]

27. Shi, M.; Zhu, J.; Wang, R.; Chen, X.; Mi, L.; Walz, T.; Springer, T.A. Latent TGF-beta structure and activation. Nature 2011, 474, 343-349. [CrossRef] [PubMed]

28. Forsten-Williams, K.; Chua, C.C.; Nugent, M.A. The kinetics of FGF-2 binding to heparan sulfate proteoglycans and MAP kinase signaling. J. Theor. Biol. 2005, 233, 483-499. [CrossRef]

29. Lyon, M.; Rushton, G.; Gallagher, J.T. The interaction of the transforming growth factor-betas with heparin/heparan sulfate is isoform-specific. J. Biol. Chem. 1997, 272, 18000-18006. [CrossRef]

30. Irie, A.; Habuchi, H.; Kimata, K.; Sanai, Y. Heparan sulfate is required for bone morphogenetic protein-7 signaling. Biochem. Biophys. Res. Commun. 2003, 308, 858-865. [CrossRef]

31. Praxenthaler, H.; Kramer, E.; Weisser, M.; Hecht, N.; Fischer, J.; Grossner, T.; Richter, W. Extracellular matrix content and WNT/beta-catenin levels of cartilage determine the chondrocyte response to compressive load. Biochim. Biophys. Acta Mol. Basis Dis. 2018, 1864, 851-859. [CrossRef]

32. Scholtes, S.; Kramer, E.; Weisser, M.; Roth, W.; Luginbuhl, R.; Grossner, T.; Richter, W. Global chondrocyte gene expression after a single anabolic loading period: Time evolution and re-inducibility of mechano-responses. J. Cell. Physiol. 2018, 233, 699-711. [CrossRef]

33. Monaco, G.; El Haj, A.J.; Alini, M.; Stoddart, M.J. Ex Vivo Systems to Study Chondrogenic Differentiation and Cartilage Integration. J. Funct. Morphol. Kinesiol. 2021, 6, 6. [CrossRef]

34. Hall, A.C. The Role of Chondrocyte Morphology and Volume in Controlling Phenotype-Implications for Osteoarthritis, Cartilage Repair, and Cartilage Engineering. Curr. Rheumatol. Rep. 2019, 21, 38. [CrossRef] 
35. Kreuger, J.; Kjellen, L. Heparan sulfate biosynthesis: Regulation and variability. J. Histochem. Cytochem. Off. J. Histochem. Soc. 2012, 60, 898-907. [CrossRef]

36. Lin, X.; Wei, G.; Shi, Z.; Dryer, L.; Esko, J.D.; Wells, D.E.; Matzuk, M.M. Disruption of gastrulation and heparan sulfate biosynthesis in EXT1-deficient mice. Dev. Biol. 2000, 224, 299-311. [CrossRef]

37. Mitchell, K.J.; Pinson, K.I.; Kelly, O.G.; Brennan, J.; Zupicich, J.; Scherz, P.; Leighton, P.A.; Goodrich, L.V.; Lu, X.; Avery, B.J.; et al. Functional analysis of secreted and transmembrane proteins critical to mouse development. Nat. Genet. 2001, 28, 241-249. [CrossRef]

38. Koziel, L.; Kunath, M.; Kelly, O.G.; Vortkamp, A. Ext1-dependent heparan sulfate regulates the range of Ihh signaling during endochondral ossification. Dev. Cell 2004, 6, 801-813. [CrossRef]

39. Otsuki, S.; Hanson, S.R.; Miyaki, S.; Grogan, S.P.; Kinoshita, M.; Asahara, H.; Wong, C.H.; Lotz, M.K. Extracellular sulfatases support cartilage homeostasis by regulating BMP and FGF signaling pathways. Proc. Natl. Acad. Sci. USA 2010, 107, 10202-10207. [CrossRef]

40. Mundy, C.; Yang, E.; Takano, H.; Billings, P.C.; Pacifici, M. Heparan sulfate antagonism alters bone morphogenetic protein signaling and receptor dynamics, suggesting a mechanism in hereditary multiple exostoses. J. Biol. Chem. 2018, 293, 7703-7716. [CrossRef]

41. Ornitz, D.M. FGFs, heparan sulfate and FGFRs: Complex interactions essential for development. Bioessays News Rev. Mol. Cell. Dev. Biol. 2000, 22, 108-112. [CrossRef]

42. Paine-Saunders, S.; Viviano, B.L.; Economides, A.N.; Saunders, S. Heparan sulfate proteoglycans retain Noggin at the cell surface: A potential mechanism for shaping bone morphogenetic protein gradients. J. Biol. Chem. 2002, 277, 2089-2096. [CrossRef]

43. Bougault, C.; Aubert-Foucher, E.; Paumier, A.; Perrier-Groult, E.; Huot, L.; Hot, D.; Duterque-Coquillaud, M.; Mallein-Gerin, F. Dynamic compression of chondrocyte-agarose constructs reveals new candidate mechanosensitive genes. PLoS ONE 2012, 7 , e36964. [CrossRef] [PubMed]

44. Wright, M.O.; Nishida, K.; Bavington, C.; Godolphin, J.L.; Dunne, E.; Walmsley, S.; Jobanputra, P.; Nuki, G.; Salter, D.M. Hyperpolarisation of cultured human chondrocytes following cyclical pressure-induced strain: Evidence of a role for alpha 5 beta 1 integrin as a chondrocyte mechanoreceptor. J. Orthop. Res. Off. Publ. Orthop. Res. Soc. 1997, 15, 742-747. [CrossRef] [PubMed]

45. Chowdhury, T.T.; Salter, D.M.; Bader, D.L.; Lee, D.A. Integrin-mediated mechanotransduction processes in TGFbeta-stimulated monolayer-expanded chondrocytes. Biochem. Biophys Res. Commun. 2004, 318, 873-881. [CrossRef]

46. Pecchi, E.; Priam, S.; Gosset, M.; Pigenet, A.; Sudre, L.; Laiguillon, M.C.; Berenbaum, F.; Houard, X. Induction of nerve growth factor expression and release by mechanical and inflammatory stimuli in chondrocytes: Possible involvement in osteoarthritis pain. Arthritis Res. Ther. 2014, 16, R16. [CrossRef]

47. Pufe, T.; Lemke, A.; Kurz, B.; Petersen, W.; Tillmann, B.; Grodzinsky, A.J.; Mentlein, R. Mechanical overload induces VEGF in cartilage discs via hypoxia-inducible factor. Am. J. Pathol. 2004, 164, 185-192. [CrossRef]

48. Krase, A.; Abedian, R.; Steck, E.; Hurschler, C.; Richter, W. BMP activation and Wnt-signalling affect biochemistry and functional biomechanical properties of cartilage tissue engineering constructs. Osteoarthr. Cartil. 2014, 22, 284-292. [CrossRef]

49. Matsumoto, Y.; Matsumoto, K.; Irie, F.; Fukushi, J.; Stallcup, W.B.; Yamaguchi, Y. Conditional ablation of the heparan sulfatesynthesizing enzyme Ext1 leads to dysregulation of bone morphogenic protein signaling and severe skeletal defects. J. Biol. Chem. 2010, 285, 19227-19234. [CrossRef]

50. Huegel, J.; Mundy, C.; Sgariglia, F.; Nygren, P.; Billings, P.C.; Yamaguchi, Y.; Koyama, E.; Pacifici, M. Perichondrium phenotype and border function are regulated by Ext1 and heparan sulfate in developing long bones: A mechanism likely deranged in Hereditary Multiple Exostoses. Dev. Biol. 2013, 377, 100-112. [CrossRef]

51. Piombo, V.; Jochmann, K.; Hoffmann, D.; Wuelling, M.; Vortkamp, A. Signaling systems affecting the severity of multiple osteochondromas. Bone 2018, 111, 71-81. [CrossRef]

52. Jones, K.B.; Piombo, V.; Searby, C.; Kurriger, G.; Yang, B.; Grabellus, F.; Roughley, P.J.; Morcuende, J.A.; Buckwalter, J.A.; Capecchi, M.R.; et al. A mouse model of osteochondromagenesis from clonal inactivation of Ext1 in chondrocytes. Proc. Natl. Acad. Sci. USA 2010, 107, 2054-2059. [CrossRef]

53. Sgariglia, F.; Candela, M.E.; Huegel, J.; Jacenko, O.; Koyama, E.; Yamaguchi, Y.; Pacifici, M.; Enomoto-Iwamoto, M. Epiphyseal abnormalities, trabecular bone loss and articular chondrocyte hypertrophy develop in the long bones of postnatal Ext1-deficient mice. Bone 2013, 57, 220-231. [CrossRef]

54. Loeser, R.F. Integrins and chondrocyte-matrix interactions in articular cartilage. Matrix Biol. J. Int. Soc. Matrix Biol. 2014, 39, 11-16. [CrossRef]

55. Lucchinetti, E.; Bhargava, M.M.; Torzilli, P.A. The effect of mechanical load on integrin subunits alpha5 and beta1 in chondrocytes from mature and immature cartilage explants. Cell Tissue Res. 2004, 315, 385-391. [CrossRef]

56. Olsen, O.E.; Wader, K.F.; Hella, H.; Mylin, A.K.; Turesson, I.; Nesthus, I.; Waage, A.; Sundan, A.; Holien, T. Activin A inhibits BMP-signaling by binding ACVR2A and ACVR2B. Cell Commun. Signal. Ccs 2015, 13, 27. [CrossRef]

57. Vernon, L.; Abadin, A.; Wilensky, D.; Huang, C.Y.; Kaplan, L. Subphysiological compressive loading reduces apoptosis following acute impact injury in a porcine cartilage model. Sports Health 2014, 6, 81-88. [CrossRef]

58. Lee, M.S.; Trindade, M.C.; Ikenoue, T.; Goodman, S.B.; Schurman, D.J.; Smith, R.L. Regulation of nitric oxide and bcl-2 expression by shear stress in human osteoarthritic chondrocytes in vitro. J. Cell. Biochem. 2003, 90, 80-86. [CrossRef] 
59. Loening, A.M.; James, I.E.; Levenston, M.E.; Badger, A.M.; Frank, E.H.; Kurz, B.; Nuttall, M.E.; Hung, H.H.; Blake, S.M.; Grodzinsky, A.J.; et al. Injurious mechanical compression of bovine articular cartilage induces chondrocyte apoptosis. Arch. Biochem. Biophys. 2000, 381, 205-212. [CrossRef]

60. Zamora, R.; Alarcon, L.; Vodovotz, Y.; Betten, B.; Kim, P.K.; Gibson, K.F.; Billiar, T.R. Nitric oxide suppresses the expression of Bcl-2 binding protein BNIP3 in hepatocytes. J. Biol. Chem. 2001, 276, 46887-46895. [CrossRef]

61. Gosset, M.; Berenbaum, F.; Thirion, S.; Jacques, C. Primary culture and phenotyping of murine chondrocytes. Nat. Protoc. 2008, 3, 1253-1260. [CrossRef] [PubMed]

62. Farndale, R.; Buttle, D.; Barrett, A. Improved quantitation and discrimination of sulphated glycosaminoglycans by use of dimethylmethylene blue. Biochim. Biophys. Acta (BBA) Gen. Subj. 1986, 883, 173-177. [CrossRef]

63. Tusher, V.G.; Tibshirani, R.; Chu, G. Significance analysis of microarrays applied to the ionizing radiation response. Proc. Natl. Acad. Sci. USA 2001, 98, 5116-5121. [CrossRef] [PubMed] 